\title{
A comparison of on-line and off-line bioaerosol measurements at a biowaste site
}

\author{
Patrick Feeney \\ University College Cork \\ Santiago Fernández Rodríguez \\ Universidad de Extremadura \\ Rafael Molina \\ Universidad de Extremadura
}

See next page for additional authors

Follow this and additional works at: https://arrow.tudublin.ie/scschcpsart

Part of the Chemistry Commons, and the Environmental Sciences Commons

\section{Recommended Citation}

Patrick Feeney, Santiago Fernández Rodríguez, Rafael Molina, Eoin McGillicuddy, Stig Hellebust, Michael Quirke, Shane Daly, David O'Connor, John Sodeau, A comparison of on-line and off-line bioaerosol measurements at a biowaste site, Waste Management, Volume 76, 2018, Pages 323-338, ISSN 0956-053X, DOI: 10.1016/j.wasman.2018.02.035.

This Article is brought to you for free and open access by the School of Chemical and Pharmaceutical Sciences at ARROW@TU Dublin. It has been accepted for inclusion in Articles by an authorized administrator of ARROW@TU Dublin. For more information, please contact arrow.admin@tudublin.ie, aisling.coyne@tudublin.ie, gerard.connolly@tudublin.ie.

Funder: Irish Research Council; EPA

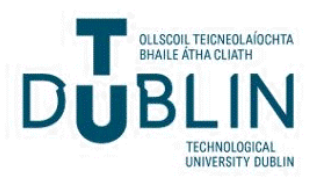




\section{Authors}

Patrick Feeney, Santiago Fernández Rodríguez, Rafael Molina, Eoin McGillicuddy, Stig Hellebust, Michael Quirke, Shane Daly, David O'Connor, and John Sodeau 


\title{
A comparison of on-line and off-line bioaerosol measurements at a biowaste site
}

\author{
Patrick Feeney ${ }^{\mathrm{a}}$, Santiago Fernández Rodríguez ${ }^{\mathrm{b}}$, Rafael Molina ${ }^{\mathrm{c}}$, Eoin McGillicuddy ${ }^{\mathrm{d}}$, Stig Hellebust ${ }^{\mathrm{a}}$, \\ Michael Quirke ${ }^{a}$, Shane Daly ${ }^{\mathrm{a}}$, David O'Connor ${ }^{\mathrm{d}}$, John Sodeau ${ }^{\mathrm{a}, *}$ \\ a School of Chemistry and Environmental Research Institute, University College Cork, Cork, Ireland \\ ${ }^{\mathrm{b}}$ School of Technology, University of Extremadura, Cáceres, Spain \\ ${ }^{\mathrm{c}}$ Faculty of Science, University of Extremadura, Badajoz, Spain \\ ${ }^{\mathrm{d}}$ School of Chemical and Pharmaceutical Sciences, Dublin Institute of Technology, Dublin, Ireland
}

\section{A R T I C L E I N F O}

\section{Article history:}

Received 19 April 2017

Revised 9 January 2018

Accepted 15 February 2018

Available online 22 February 2018

\section{Keywords:}

Compost

Bioaerosols

Fluorescence detection

Optical microscopy

\begin{abstract}
A B S T R A C T
An air measurement campaign was carried out at a green-waste composting site in the South of Ireland during Spring 2016. The aim was to quantify and identify the levels of Primary Biological Aerosol Particles (PBAP) that were present using the traditional off-line, impaction/optical microscopy method alongside an on-line, spectroscopic approach termed WIBS (Wideband Integrated Bioaerosol Sensor), which can provide number concentrations, sizes and "shapes" of airborne PBAP in real-time by use of Light Induced Fluorescence (LIF). The results from the two techniques were compared in order to validate the use of the spectroscopic method for determining the releases of the wide-range of PBAP present there as a function of site activity and meteorological conditions. The seven-day monitoring period undertaken was much longer than any real-time studies that have been previously performed and allowed due comparison between weekday (working) activities at the site and weekend (closed) releases. The time-span also allowed relationships between site activities like turning, agitation or waste delivery and the WIBS data to be determined in a quantitative manner. This information cannot be obtained with the Andersen Sampling methods generally employed at green-waste management sites. Furthermore, few specific bioaerosol types other than Aspergillus fumigatus, are identified using the traditional protocols employed for site licensing purposes. Here though the co-location of WIBS with the impaction instrument made it possible to identify the real-time release behaviour of a specific plant pathogenic spore, Ustilago maydis, present after green-waste deliveries were made by a local distillery.
\end{abstract}

(c) 2018 Elsevier Ltd. All rights reserved.

\section{Introduction}

The air quality determined for indoor or outdoor ambient or occupational environments is significantly affected by the levels of particulate matter present. The health risks associated with particulate matter $\left(\mathrm{PM}_{10}, \mathrm{PM}_{2.5}\right.$ and $\left.\mathrm{PM}_{1}\right)$, mainly generated by combustion processes and from non-exhaust vehicle emissions, are well known (Pöschl, 2005, Cohen et al., 2005). Although the effects on humans and plant life of corresponding biological particulate matter (termed Primary Biological Aerosol Particles, PBAP, or bioaerosols) have been studied for many years (Pinnick et al., 1995, Després et al., 2012, Poehlker et al., 2012), the real-time monitoring of this type of airborne material at known "hot-spot" locations such as composting sites has lagged behind. Hence there

\footnotetext{
* Corresponding author.

E-mail address: j.sodeau@ucc.ie (J. Sodeau).
}

are few studies published that quantify the number and type of fungal spores being released at places where individuals (particularly those who are immuno-compromised) are present or where susceptible crops may be affected on a routine basis. Greenwaste management sites are a good example of such outdoor spaces that are often found in rural areas close to crops, served by staff and visited by customers. There are licensing guidelines set by national and regional environmental agencies for commercial composting operations. These primarily focus on people inhabiting the surrounding areas and for site workers themselves. On Irish compost sites the monitoring of a limited number of harmful biological particles like Aspergillus fumigatus, are performed off-site just once a year for a short time period with the results returned some days later to the local management (Williams et al., 2013, O'Connor et al., 2015). Therefore no indication of minute-tominute or hour-to-hour changes in bioaerosol releases are made even when the normal agitation processes associated with the 
composting process occur or when deliveries are made. The English Environment Agency guidance specifies that to be deemed acceptable, monitoring should be carried out at times of high site activity e.g. turning, shredding, screening.

One of the most important aims of the waste industry is to maximise the benefit that can be recovered from global waste. Composting is a method of waste management that is based on the biological degradation and stabilisation of organic matter performed under aerobic conditions (Sanchez-Monedero et al., 2005, Wéry, 2014, Avery et al., 2012, Beffa et al., 1998, Hryhorczuk et al., 2001). However, it has now become an important industrial activity, which impacts on waste management targets. Therefore, a substantial increase, throughout the world, has become apparent for the use of local composting facilities to manage and utilize green- and food-waste (Hryhorczuk et al., 2001, Wéry, 2014, Recer et al., 2001).

Many of the microbial processes involved in the degradation and transformation processes from green-waste to fertilizer are now understood and airborne bioaerosols are a natural, unavoidable outcome of the processing. Hence there can be major releases of sometimes pathogenic and irritant bioaerosols at composting sites especially during activities involving the vigorous movement of material such as shredding, compost pile turning and compost screening (Wéry, 2014, Taha et al., 2006, Sanchez-Monedero et al., 2005, Hryhorczuk et al., 2001, Millner et al., 1980, Taha et al., 2005, Gillum and Levetin, 2008, Sanchez-Monedero and Stentiford, 2003, Pankhurst et al., 2011). The increased emissions of bioaerosols are currently causing concerns related to potential, occupational health impacts on the workers, visitors to commercial composting facilities and nearby residents (Sanchez-Monedero et al., 2005, Wéry, 2014, Van der Werf, 1996). Furthermore, certain crops in the site vicinity have the potential to be harmed. Of course, the human health aspect is the reason why licensing authorities have put in place (although only in some countries) regimes where monitoring techniques involving the impaction of viable microorganisms onto a culture e.g. Andersen Sampling must be used to measure levels of mesophilic bacteria and the fungal spore Aspergillus fumigatus (Williams et al., 2013, Pankhurst et al., 2011).

Typical mass concentrations for fungal spores of $\sim 1 \mu \mathrm{g} \mathrm{m} \mathrm{m}^{-3}$ are found in continental boundary layer air with estimated global emissions being $\sim 50 \mathrm{Tg} / \mathrm{yr}$ (Poehlker et al., 2012, Elbert et al., 2007). Fungal spores are the most abundant of the PBAP to be found in many local environments (Després et al., 2012, Elbert et al., 2007, Womiloju et al., 2003) and occur wherever decaying vegetation is present as it provides a food/energy source. The average size of these spores sits in the range between 2 and $10 \mu \mathrm{m}$ $\left(\mathrm{PM}_{2.5}\right.$ and $\left.\mathrm{PM}_{10}\right)$ (Simon-Nobbe et al., 2007) and therefore potentially have adverse health effects on humans. For example their presence has long been associated with asthma and other reactive airway diseases such as allergic bronchopulmonary mycoses, rhinitis, allergic sinusitis, hypersensitivity pneumonitis and allergic aspergillosis (Simon-Nobbe et al., 2007, Chaudhary and Marr, 2011). Deterioration in the pulmonary function of people with chronic asthma and cystic fibrosis and pathogenicity in immunecompromised people e.g. patients undergoing chemotherapies for cancer are of particular concern to the medical community.

The current regulation set by the English Environment Agency (and adopted by the Irish EPA) is for compost sites to demonstrate "acceptable levels" of mesophilic bacteria $\left(10^{3} \mathrm{CFU} \mathrm{m}{ }^{-3}\right)$ and the fungal spore Aspergillus fumigatus ( $500 \mathrm{CFU} \mathrm{m}^{-3}$ ) (Williams et al., 2013, Pankhurst et al., 2011). The benchmarks have been set as a $\times 10$ factor relative to outdoor ambient levels. Aspergillus fumigatus is monitored as a total marker for fungal spore emissions on compost sites. It is a known human pathogen (Simon-Nobbe et al., 2007, Horner et al., 1995, Fischer et al., 1998, Abba, 2004) with compost heaps being an environmental source of the spore due not only to the self-heating process but also to the intrinsic thermo-tolerance of the spore (Vincken and Roels, 1984, Gillum and Levetin, 2008, Van der Werf, 1996, Millner et al., 1977). Hence composting plant operations must be located $250 \mathrm{~m}$ from any other property in the vicinity (Sanchez-Monedero et al., 2005).

Andersen sampling is the current method of choice used for determining the concentrations of mesophilic bacteria and Aspergillus fumigatus at compost sites although IOM or CEN filters followed by culture in the laboratory may also be used. It is a traditional off-line technique for monitoring bioaerosols and relies on pumped air impaction onto an agar gel. The collected samples are then returned to the laboratory for further cultivation (Després et al., 2012). The technique has two major limitations: (i) it only measures the spores and bacteria that are viable for its specific media and (ii) it only collects a small volume of air, offsite, for a short period of time (Hryhorczuk et al., 2001). The reason for making collections over $2-10$ min spans is because, as the micro-organisms are impacted directly onto the agar surface, there is a danger of the plate becoming overloaded in environments that give rise to high concentrations. Compost sites are a good example of this possibility and so sampling is never performed on-site when using Andersen sampling, rather 100-250 m upwind and downwind from the source in Ireland (Cartwright et al., 2009, Eduarda and Heederik, 1998, Williams et al., 2013).

Andersen sampling does not provide a comprehensive list of fungal spores that may be emitted from a green-waste site and in order to undertake such a counting and identification regime an impaction/optical microscopy approach was used in this campaign. The equipment was set up, on site and adjacent to a realtime monitor for biological/fluorescent particulates. This novel approach gave a direct comparison between the traditional aerobiological method that provided unequivocal information about the number and identity of many fungal spores in local air with an instrumental technique, based on intrinsic fluorescence and optical scatter measurements of airborne particulates, termed the Wideband Integrated Bioaerosol Sensor (WIBS). The model used on this campaign (WIBS-4A) was manufactured by Droplet Measurement Technologies.

The WIBS instrument has now been utilized in many field campaigns directed to the measurement of bioaerosols. It has been deployed in a number of locations around the world from tropical rainforests (Gabey et al., 2010) to urban/rural and coastal sites to measure outdoor ambient air (Healy et al., 2014, Crawford et al., 2014). However, it has only been deployed and reported in the literature once before in an outdoor green-waste occupational setting, albeit for a very short period of time (1-2 days) (O'Connor et al., 2015).

In the seven-day, outdoor, on-site campaign reported here online continual measurements of fluorescent and non-fluorescent particles released from a green-waste site have been quantified using the WIBS method. The data obtained are then compared to those obtained using a Hirst-type, impaction device (followed by analysis using optical microscopy). The monitoring period undertaken was much longer than any real-time studies that have been previously performed and allowed due comparison between weekday (working) activities at the site and weekend (closed) releases. The time-span also allowed relationships between site activities like turning, agitation or waste delivery and the WIBS data to be determined in a quantitative manner. This information cannot be obtained with the Andersen Sampling methods generally employed at green-waste management sites. Furthermore, few specific bioaerosol types other than Aspergillus fumigatus, are identified using the traditional protocols employed for site licensing purposes. Here though the co-location of WIBS with the impaction 
instrument made it possible to identify the real-time release behaviour of a specific plant pathogenic spore, Ustilago maydis, present after green-waste deliveries were made by a local distillery.

\section{Methodology}

\subsection{WIBS instrumentation}

The WIBS-4A instrument (Droplet Measurement Technologies, Boulder, Colorado, USA) is a robust, compact, portable on-line Light Induced Fluorescence (LIF) and optical scattering instrument (Kaye and Stanley, 2014). Although it counts all particles in the 0.5-15 $\mu \mathrm{m}$ range it is able to detect specifically those that are fluorescent. Information about their size and "shape" is also collected (Kaye and Stanley, 2014, Healy et al., 2012). Particle shape (asphericity) is determined by measurement of the forward scattered light onto a quadrant PMT detector. An Asymmetry Factor (AF) is calculated taking values between 1 and 100 where 1 is assigned to a perfect sphere and where rod-like, fibres have a value of 100 (Gabey et al., 2013, Toprak and Schnaiter, 2013). In terms of its operation, two xenon flash lamps are used to excite PBAP biofluorophores at $280 \mathrm{~nm}$ and $370 \mathrm{~nm}$ with emission captured in two ranges, 310$400 \mathrm{~nm}$ and 420-650 nm (Healy et al., 2012, Kaye and Stanley, 2014, Gabey et al., 2010, Kaye et al., 2004, Toprak and Schnaiter, 2013). This arrangement leads to three detection channels which are called the FL1, FL2 and FL3 detection channels. On the FL1 channel the particle is excited at $280 \mathrm{~nm}$ and emission is detected in the $310-400 \mathrm{~nm}$ detector. The FL2 channel excites the particle at $370 \mathrm{~nm}$ and emission is detected on the 420-650 nm waveband detector. The FL3 channel excites particles at $370 \mathrm{~nm}$ and emission is detected on the $420-650 \mathrm{~nm}$ waveband detector (Toprak and Schnaiter, 2013). There is a low level of background fluorescence present in the optical chamber of the WIBS. Hence the base-line fluorescence intensity must be determined. Forced trigger values are calculated to determine this base-line fluorescence intensity for each WIBS fluorescence channel, FL1, FL2 and FL3. This is achieved by running the instrument without the pump on and thus the fluorescence levels of the optical chamber are determined. If a sampled particle has an intensity higher than the average baselines plus three times the standard deviation it is classed as a fluorescent particle (Toprak and Schnaiter, 2013, Gabey et al., 2010). Full descriptions of the operating parameters of the WIBS technique have been given elsewhere (Gabey et al., 2010, Toprak and Schnaiter, 2013, Kaye and Stanley, 2014). Field campaigns using the WIBS have also been described in several previous reports along with the limitations encountered when applying the methodology (Toprak and Schnaiter, 2013, Gabey et al., 2010, Gabey et al., 2013, Crawford et al., 2014, Healy et al., 2014, O'Connor et al., 2015).

\subsection{SporeWatch/optical microscopy}

The "SporeWatch: Electronic Spore and Pollen Sampler" which is manufactured by Burkard Scientific, UK, was also used on this campaign. It was positioned $3 \mathrm{~m}$ from the ground. A narrow orifice is directed into the wind which sucks in fungal spores onto a silicone tape surface that is moved across the orifice at $2 \mathrm{~mm} / \mathrm{h}$ with a suction rate of $10 \mathrm{~L} / \mathrm{min}$. The silicone tape is adhered onto a rotating drum, it has a 7-day sampling period. At the end of the sampling period the drum was returned to the laboratory and the tape cut into 7 equal segments, each representing a 24-h period i.e. A sample comprising of one day of collection is then deposited on a tape area of $48 \times 14 \mathrm{~mm}$ (Hirst, 1952), which is then affixed to a microscope slide. The microscope slides were prepared, stored in a protective casing and sent to the University of Extremadura,
Badajoz in Spain where the counting was performed by members of their Aerobiology research group. The optical microscope used for counting was a Nikon Eclypse model with a magnification of $\times 1000$. The movement of the sticky tape surface at a constant rate shows the changes in spore concentration with respect to time. The correlation with time also leads to a correlation with weather parameters i.e. rain, humidity, wind speed and direction.

\subsection{Campaign}

The monitoring campaign took place over a one week period from Monday 29th February to Monday 7th of March 2016. The monitoring campaign was carried out at a green-waste composting site that was located in a remote, rural location in the South of Ireland, approximately $6 \mathrm{~km}$ due North of the Irish coastline (O'Connor et al., 2015). A schematic of the site is presented in Fig. 1 . The site has a 6000 tonne capacity per year for source segregated green-wastes from different municipalities in the surrounding areas. At the site, the green-waste was shredded mechanically and stored in compost windrows, both in open air and in composting vessels where the compost was left to mature. During the maturation phase the agitation and turning of the windrows were performed using the bucket from front-end loaders which were active throughout the site for the duration of the working day. After the maturation phase the compost was mechanically screened in order to separate it into coarse and fine products. After the screening the compost was temporarily stored in a shed near the entrance of the site before it was sold to commercial or private customers. The typical working week for the employees at the facility are Monday to Thursday 08:30-17:00 and 08:30-16:00 on a Friday. The compost site was closed at the weekend. During the operating hours of the facility there was constant on-site activity from the deliveries of green-waste to the site to the loading of finished compost for sale. Front-end loaders were also regularly in use for either sorting deliveries, loading compost sales, loading the green-waste to the shredder, pile turning or the loading of the screening machine to separate the oversize waste from the compost.

The SporeWatch and the WIBS-4A were co-located at one sampling point at the North corner on the composting site. The WIBS$4 \mathrm{~A}$ was housed in a mobile trailer with an air inlet. The SporeWatch was attached to the roof of the trailer. They were approximately 1 $m$ away from each other. Both instruments were therefore essentially measuring the same air samples. To the east of the trailer there was a ditch separating it from a farm which was $\sim 30 \mathrm{~m}$ in distance away. There was a compost windrow to the south of the trailer and a screener machine was located to the west. The largest compost shed on-site was located north-west of the trailer and the bio-filter was to the north. Deliveries arrived and were unloaded $\sim 100 \mathrm{~m}$ to the south-southwest direction of the trailer. There was a machine for shredding green waste located by the delivery area of the site (see schematic) however it was inactive for the duration of the campaign.

The real-time data recorded by the WIBS was also correlated with weather parameters. The weather data from the site was measured with a Casella Nomad Weather Station.

\subsection{Data analysis}

The conversions and data analysis of the impacted spores were carried out using Microsoft Excel 2013 and graphing is presented with Igor Pro 6.37.

The WIBS-4A recorded its raw data on excel files. A single excel file contained a maximum of 30,000 particles or up to a maximum time duration of $3 \mathrm{~h}$. Throughout the one-week measurement period (29th February - 6th March) there was a total of 273 raw excel 


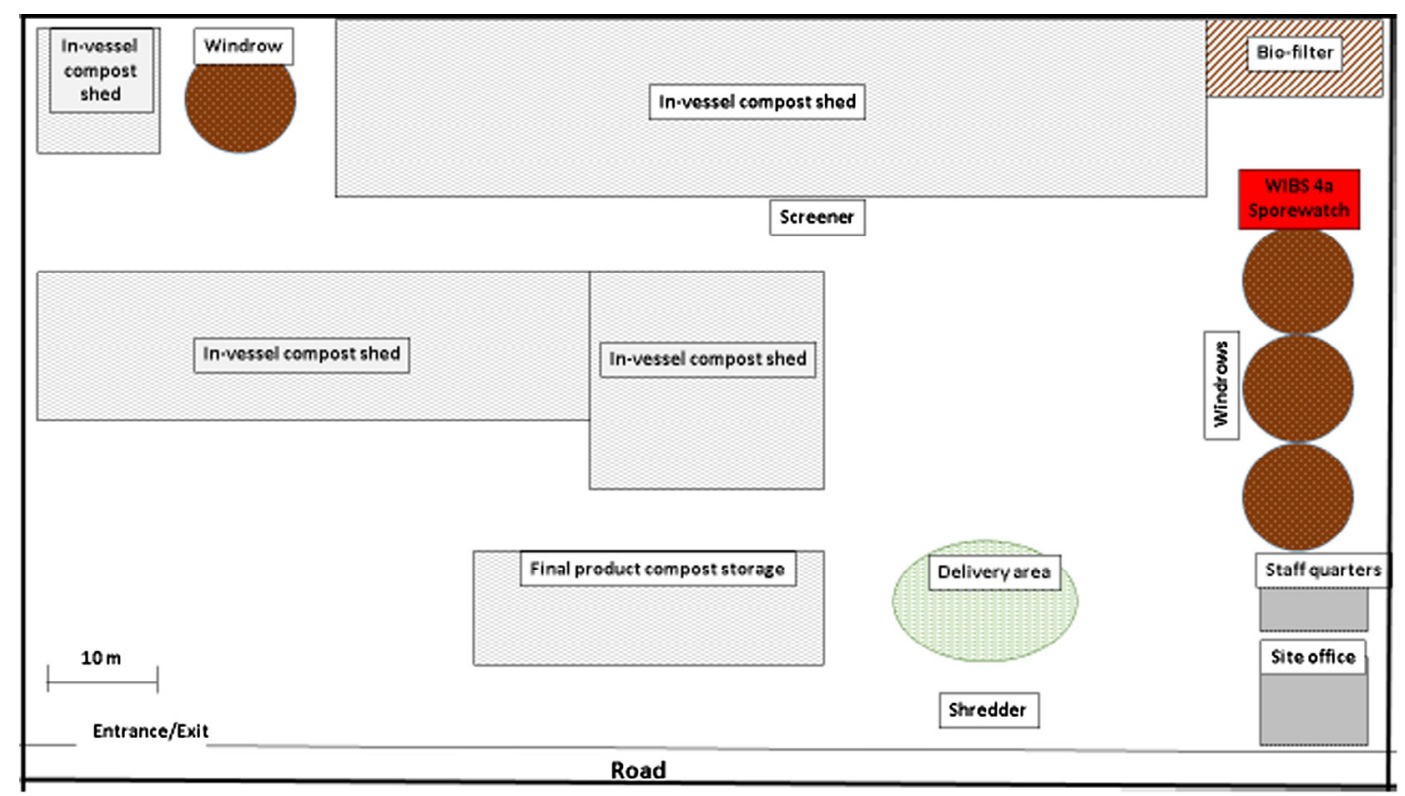

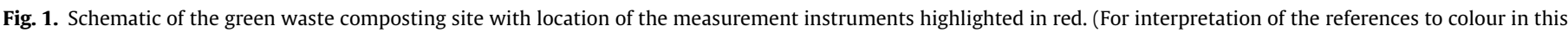
figure legend, the reader is referred to the web version of this article.)

files collected. These data were imported into MATLAB (Math Works Inc., USA) and processed further into appropriate files, subsets and matrices. They were then analysed with Microsoft Excel 2013 and graphed using Igor Pro 6.37.

\section{Results and discussion}

The spores measured by the SporeWatch/Optical microscope combination are presented below as hourly concentrations for the seven-day measurement campaign. A total of 169 hourly concentrations were recorded.

The following 23 different species of fungal spores were measured on-site and identified by appearance: Aspergillus/Penicillium, Ustilago maydis, Coprinus, Leptosphaeria, Coprinus, Cladosporium cladosporioides, Ustilago cynodontis, Diatrype, Arthrinium, Cladosporium herbarum, Venturia, Pleospora, Alternaria, Drechslera, Xanthoria, Massaria, Agrocybe, Oidium, Epicoccum, Ganoderma, Telephora, Stemphylium solani and Curvularia.

Aspergillus and Penicillium were grouped together when counting. This is common protocol as they are similar in size and indistinguishable under an optical microscope (Hryhorczuk et al., 2001, Gillum and Levetin, 2008). Aspergillus fumigatus is a dominant fungal spore where there is decaying vegetation i.e. compost piles as it is a thermo-tolerant spore which enables it to survive the high temperatures reached in the composting process (Fischer et al., 1998, Millner et al., 1980, Sugui et al., 2011). However Penicillium has also been measured in moderate amounts on composting sites using Andersen Sampling (Hryhorczuk et al., 2001, Fischer, 2000).

The six most dominant spores, with their contributing percentages in relation to total spore numbers are displayed in Fig. 2. A table of descriptive statistics (mean, mode, median, standard deviation) for their hourly concentrations is presented Table 1.

Clearly, Aspergillus/Penicillium gave rise to the highest airborne concentrations similar to that found previously in a study at a composting facility using Andersen Sampling in a 10-day campaign (Hryhorczuk et al., 2001). In fact the spores here contributed $32.80 \%$ of the total spores measured over the full campaign showing an average hourly concentration of 319 spores $/ \mathrm{m}^{3}$ and a total of 53,942 spores.
The spore with the second highest concentration measured on the compost-site was Ustilago maydis which made up $25.25 \%$ of the total spores measured over the entire campaign. Ustilago maydis is a Basidiospore in the class Ustomycetes in the order Ustilaginales or smuts (Carlile et al., 2001). The total number of spores measured over the campaign was 41,530 with an average hourly concentration of 246 spores $/ \mathrm{m}^{3}$. The standard deviation from the average was very high at 1672 , which indicated that large variations occurred from the average hourly concentrations. This observation is likely because the spore was measured mainly at certain major spore release plumes; its concentrations were low at other times throughout the campaign. The behaviour is discussed below.

Coprinus Porate, Coprinus, Leptoshaeria and Cladosporium cladosporioides occurred at much lower concentrations with a percentage of total spores of $8.26 \%, 4.58 \%, 5.32 \%$ and $4.32 \%$ respectively.

Fungal spore time-series profiles were constructed to relate the SporeWatch measurements with site activity. Such graphs, spanning the entire campaign (29th February 13:30 - 7th March 13:30) were completed for the six dominant spores on the compost site and also for total spores. The data are displayed in Figs. 3a-3c.

Fig. 3a clearly shows that, as expected for the location, spores were present throughout the campaign. Most strikingly there was a major spore release measured on Thursday the 3rd March at 16:00-17:00. It had a value of over 20,000 spores $/ \mathrm{m}^{3}$ and dominated the time series for the campaign. Notable peaks also occurred on Monday 29th at 14:00, Tuesday 1st from 09:00 to 10:00 and Friday the 4th at 09:00 which were all inside the working hours of the compost site.

Fig. 3b shows the time series for the three spores with the highest concentrations i.e. Aspergillus/Penicillium, Ustilago maydis and Coprinus porate. The data for the most abundant group shows that it occurred with an irregular presence throughout the campaign. The reason for such apparent behaviour is likely due to the spores being present in large chains/clumps that were contained in bubbles on the adhesive substrate. This phenomenon was apparent when viewing the microscope slides with the optical microscope.

Ustilago maydis, as seen in Fig. 3b, was released on only a few occasions and accounted for the large spore event measured on Thursday 3rd March (16:00-17:00), which is evident when com- 
6 most dominant Spore types

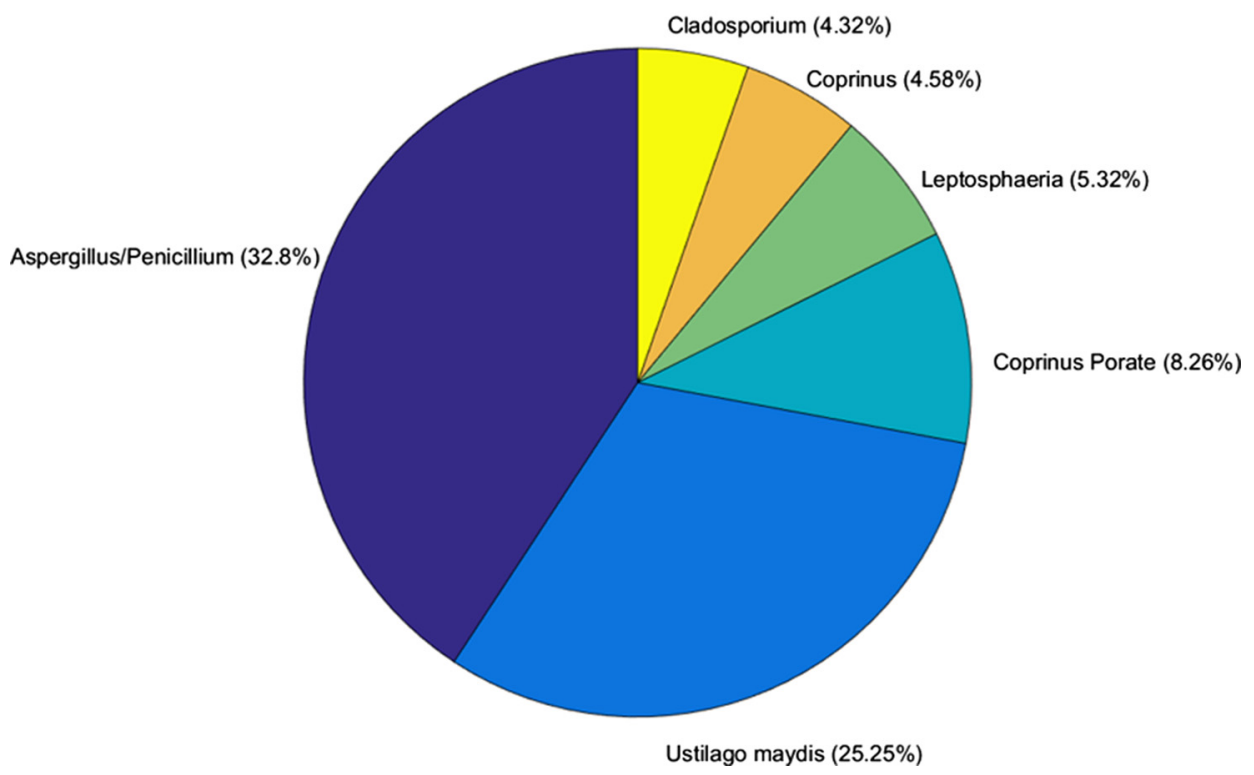

Fig. 2. 6 most common spores released from the composting site.

Table 1

Descriptive statistics of the hourly concentrations (Spores $/ \mathrm{m}^{3}$ ) of the six most common spore types measured at the composting site.

\begin{tabular}{|c|c|c|c|c|c|c|c|}
\hline & $\begin{array}{l}\text { Total spores } \\
\left(\text { Spore } / \mathrm{m}^{3}\right)\end{array}$ & $\begin{array}{l}\text { Aspergillus/Penicillium } \\
\left(\text { Spore } / \mathrm{m}^{3}\right)\end{array}$ & $\begin{array}{l}\text { Cladosporium cladosporioide } \\
\left(\text { Spore } / \mathrm{m}^{3}\right)\end{array}$ & $\begin{array}{l}\text { Leptosphaeria } \\
\left(\text { Spore } / \mathrm{m}^{3}\right)\end{array}$ & $\begin{array}{l}\text { Coprinus } \\
\left(\text { Spore } / \mathrm{m}^{3}\right)\end{array}$ & $\begin{array}{l}\text { C. Porate } \\
\left(\text { Spore } / \mathrm{m}^{3}\right)\end{array}$ & $\begin{array}{l}\text { Ustilago maydis } \\
\left(\text { Spore } / \mathrm{m}^{3}\right)\end{array}$ \\
\hline Sum & 164,477 & 53,942 & 7107 & 8752 & 7532 & 13,578 & 41,530 \\
\hline Mean & 973 & 319 & 42 & 52 & 45 & 80 & 246 \\
\hline Median & 530 & 53 & 0 & 0 & 0 & 53 & 0 \\
\hline Mode & 212 & 0 & 0 & 0 & 0 & 0 & 0 \\
\hline $\begin{array}{l}\text { Standard } \\
\text { deviation }\end{array}$ & 2077 & 568 & 131 & 115 & 103 & 110 & 1672 \\
\hline Minimum & 0 & 0 & 0 & 0 & 0 & 0 & 0 \\
\hline Maximum & 21,057 & 3342 & 1485 & 849 & 583 & 530 & 17,026 \\
\hline
\end{tabular}

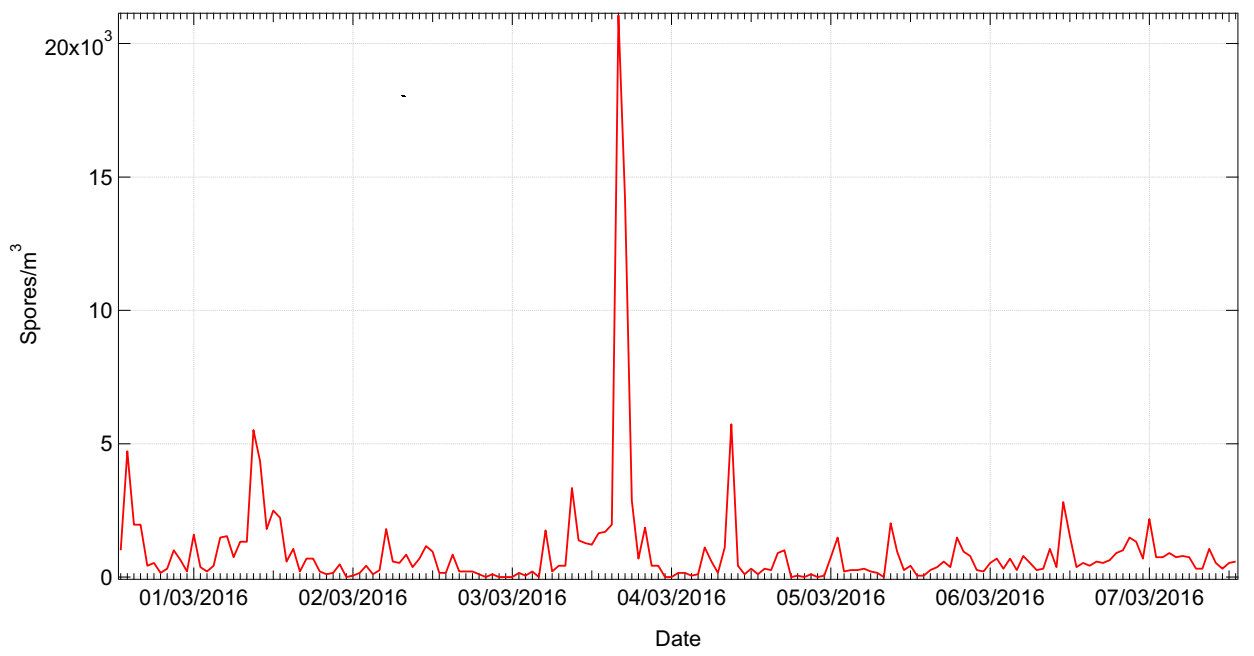

Fig. 3a. Time series graph of Total Spores vs. Time.

paring its specific time series with that of total spores (Fig. 3a). This species of fungus is a parasite occurring on maize, which was one of the green-waste types delivered to the compost site. Upon examination of the delivery logbook it was found that there were regular deliveries from a local distillery. It was determined that waste products from the distillation process included wheat, barley and maize and therefore represented the most likely source of the Ustilago maydis smut fungus determined on-site. The main 


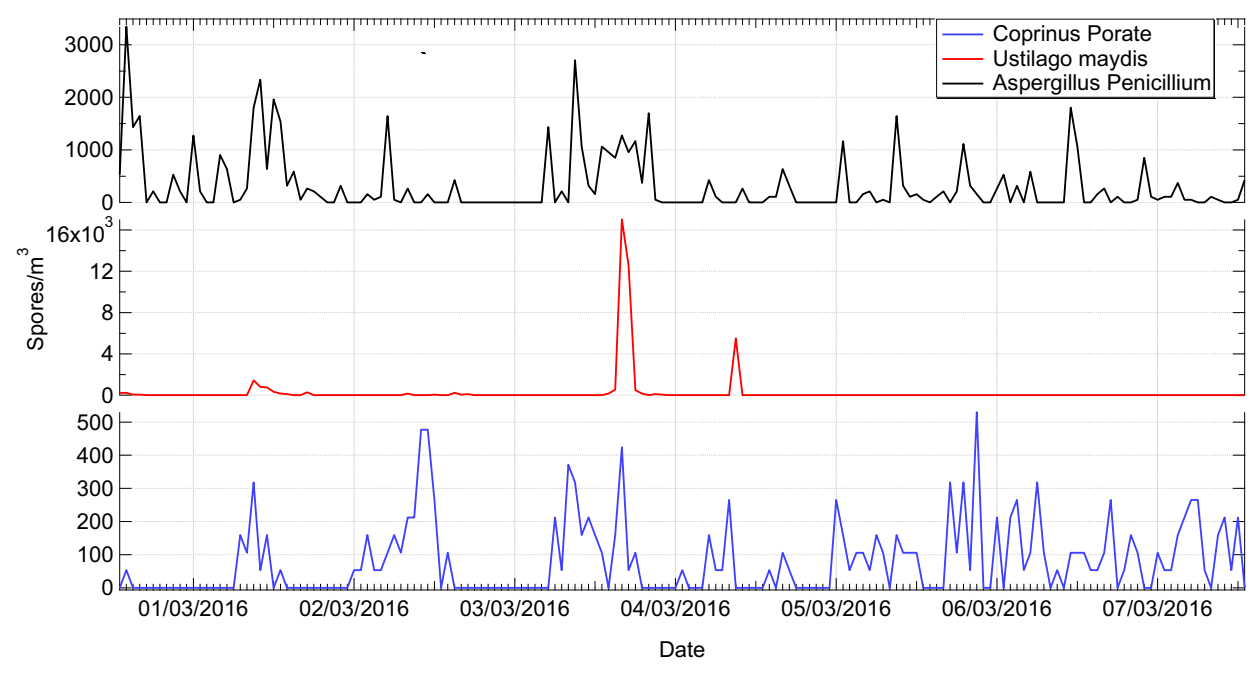

Fig. 3b. Time series of Spores vs Time for the Aspergillus/Penicillium, Ustilago maydis and Coprinus Porate.

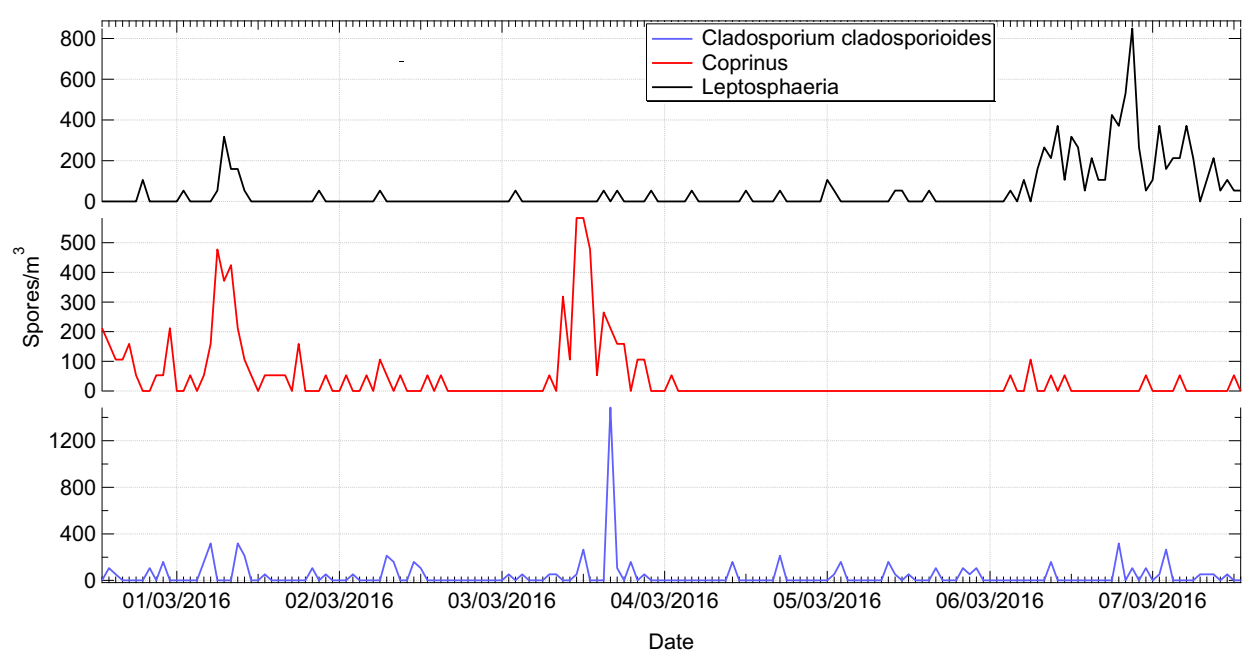

Fig. 3c. Time series of Spores vs Time for Leptosphaeri, Coprinus and Cladosporium cladosporioides.

measurements of it were Thursday 3rd March between 16:0017:00 and Friday 4th March at 09:00. There were minor measurements made Tuesday 1st March from 09:00 to 14:00.

The concentrations of Coprinus Porate (a mushroom fungus) as illustrated in Fig. 3b occurred with an irregular pattern. It was present at much lower concentrations than Aspergillus/Penicillium and Ustilago maydis and had an average hourly concentration of 80 spores $/ \mathrm{m}^{3}$.

Fig. 3c presents the time series for Leptosphaeria, Coprinus and Cladosporium cladosporioides, which had average hourly concentrations of 52, 45 and 42 spores $/ \mathrm{m}^{3}$ respectively.

A similar monitoring campaign using a SporeWatch has been performed previously. However the impactor was located $710 \mathrm{~m}$ downwind from the composting site rather than on-site as in the current study. Aspergillus/Penicillium, smut spores (in which Ustilago maydis were grouped) and Cladosporium cladosporioides were all detected during the monitoring campaign although Coprinus, Coprinus Porate and Leptosphaeria were not recorded (Gillum and Levetin, 2008).

The Fluorescence Aerosol Particle (FAP) data obtained from the WIBS measurement campaign were used to construct profiles that were complementary to the spore count numbers. The treatment includes measurements of: (i) time series; (ii) size distributions; (iii) accumulated concentration diurnal plots; (iv) correlations with meteorology data.

A total of 3,482,073 particles (fluorescent and non-fluorescent) were measured over the campaign from 29th February (13:30) to 6th March (23:59). FAP were defined by applying the measured forced trigger threshold values. The total FAP measured were 516,172 particles. This value represents $14.8 \%$ of the overall particles measured at the site. Two separate FAP site profiles were constructed for the measurement campaign. One was for the weekday period (Monday - Friday) over which time the compost site was operational during the working hours of 08:30-17:00 and the other an FAP site profile for the weekend period (Saturday - Sunday) when the compost site was formally closed and locked up.

The weekday FAP site profile was obtained over the period 29/02/2016 (13:30) to 04/03/2016 (23:59). The weekend measurement period was from Saturday (00:00) to Sunday (23:59). The weekend period was analysed separately as the measurements made were not affected by the various weekday working operations at the compost site.

Time series graphs for each period were constructed and are shown in Figs. 4a and 4b. The graphs also provided information on size and fluorescence intensities measured in the FL1 channel. Each time series was constructed with a one-hour resolution. 


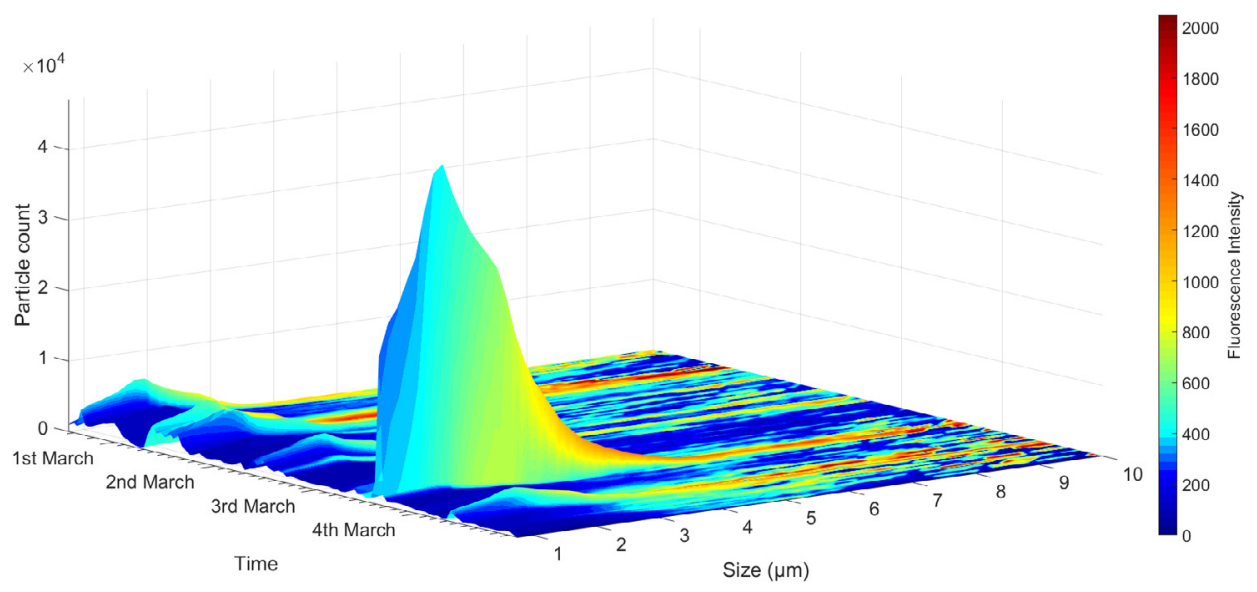

Fig. 4a. A time series profile of size and FL1 intensity for the weekdays.

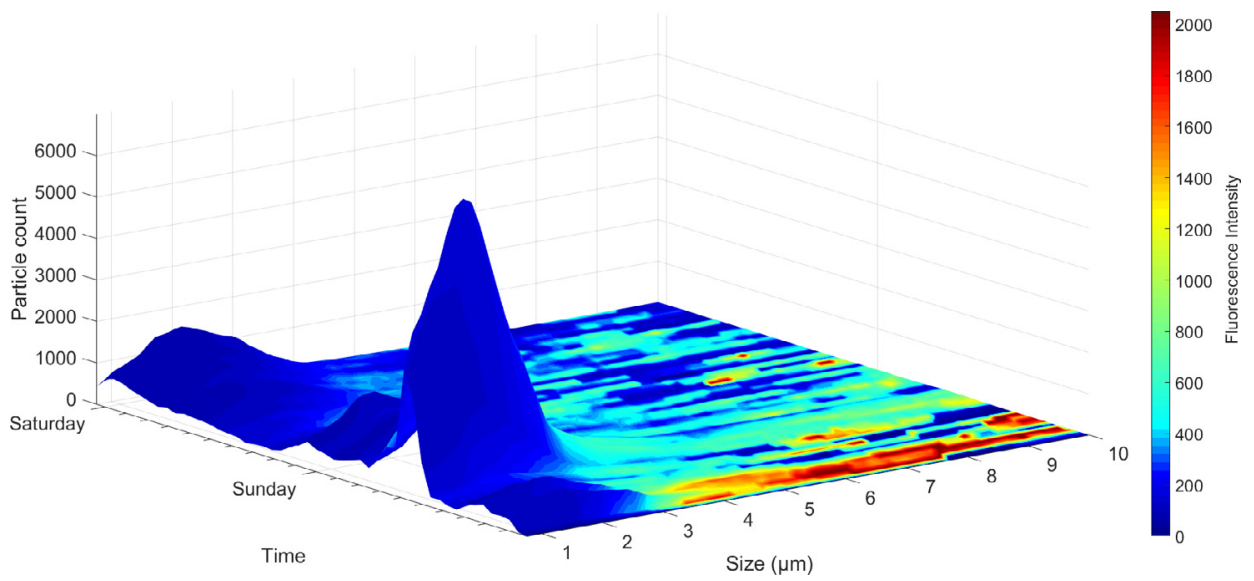

Fig. 4b. A time series graph with size and fluorescence intensity for the weekend.

Fig. 4a shows that there was a major fluorescent particle event which occurred on Thursday 3rd March at 15:00. This feature coincides with the Ustilago maydis event recorded by the SporeWatch and shown in Fig. $3 \mathrm{~b}$ albeit with far greater time resolution. The fluorescence intensity of the particles was high and ranged from $\sim 400$ to 800 for particles $<4 \mu \mathrm{m}$. This event dominated the time series for the full weekday period. The strongest fluorescent intensities $>1400$ were all associated with larger particles $(>4 \mu \mathrm{m})$ and were measured in much lower number concentrations than the smaller ones.

Fig. 4b illustrates that there was a large number concentration of FAP measured on Sunday from 07:00 to 11:00. The majority of the spores released were $<3 \mu \mathrm{m}$ and had low intensity fluorescence. The higher intensity fluorescence was associated with somewhat larger particles with their moderate fluorescence shown with the turquoise colour. Particles with very intense fluorescence (indicated on the graph with a deep red/crimson colour) occurred late on Sunday night, they were even larger particles ranging in size from 4 to $10 \mu \mathrm{m}$ and were present in a very low concentration.

To investigate the size of the particles measured over the weekday and weekend periods, accumulated hourly concentration diurnal image plots of size $(\mu \mathrm{m})$ vs time $(\mathrm{h})$ with the FAP counts in a colour key were constructed for both the weekday and weekend periods as seen in Figs. 5a and 5b.

Fig. 5a highlights that a high density of particles was measured during the weekday operational hours of the site (08:30-17:00) as can be seen by the light blue/green colour region. This finding was consistent with a similar image plot constructed from measurements made on the same composting site over a one-day period (O'Connor et al., 2015). There was also an extremely high concentration of particles determined at 16:00 which dominated the image plot with its deep red/crimson colour profile. This trend can be attributed to a large FAP event measured on Thursday 3rd March from 15:00 to 16:00. The size range of the particles measured during the working day period (08:30-17:00) were mostly in the $1-3 \mu \mathrm{m}$ size range, which is a dominant size range when monitoring FAP (O'Connor et al., 2015, Toprak and Schnaiter, 2013, Gabey et al., 2013), with highest levels at $\sim 1.7 \mu \mathrm{m}$. An increased number of these particles were measured from 21:00 to $24: 00$, most prominently at 21:00. The image plot clearly demonstrates that the compost sites activities had a major impact on FAP concentrations when it was operational (08:30-17:00) especially in the Aspergillus fumigatus and mesophilic bacteria size ranges; this finding has been demonstrated on many previous campaigns (Van der Werf, 1996, Taha et al., 2005, SanchezMonedero and Stentiford, 2003, Recer et al., 2001).

Fig. 5b illustrates that most of the higher accumulated concentrations occurred from 00:00 to 13:00 as can be seen by the light blue/green colour. It is important to note that the colour scales for Figs. 5a and 5b represent different concentration i.e. Fig. 5a has much higher concentrations than Fig. 5b. The concentrations were low during the hours of 14:00-22:00 and then they increased from 23:00 onwards. The higher concentrations of FAP occurred during the night and morning and low measurements were 


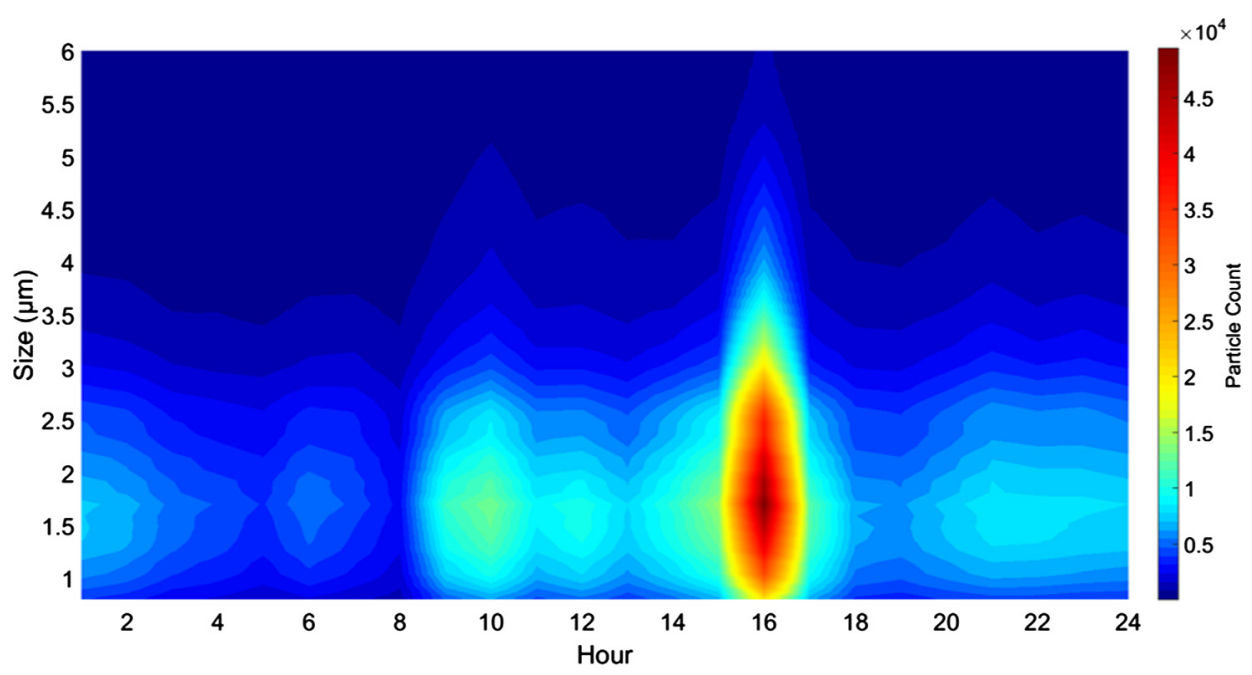

Fig. 5a. Diurnal image plot over the weekday period.

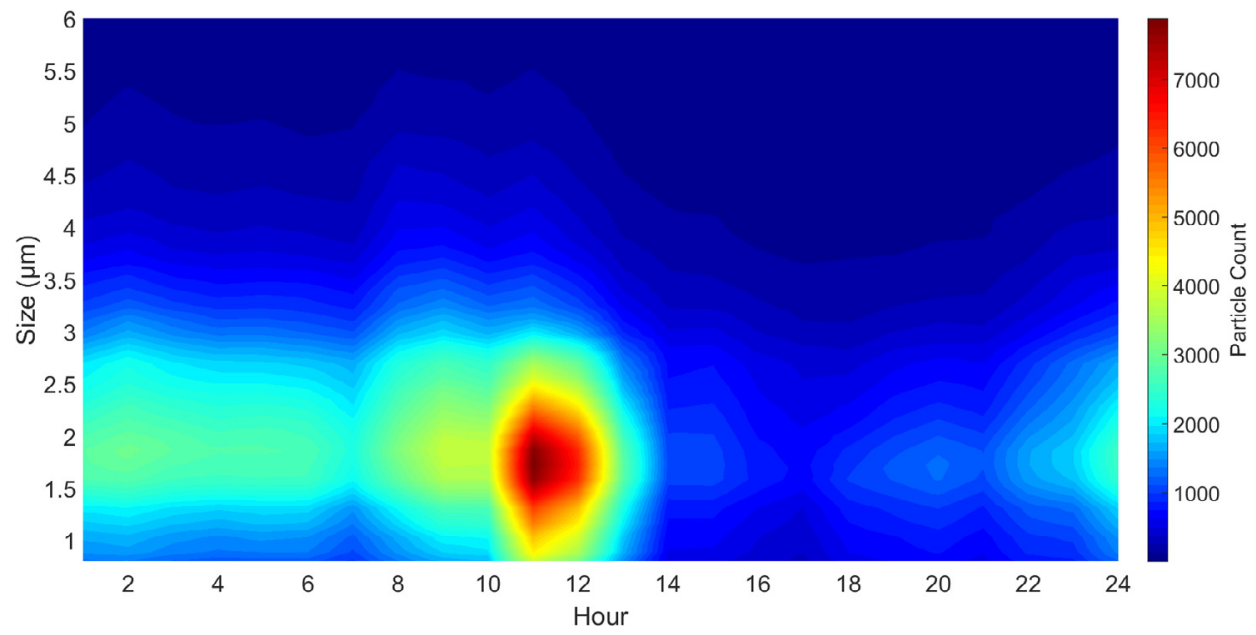

Fig. 5b. Diurnal image plot over the weekend period.

recorded in the afternoon and evening. Most of the particles measured were in the $1-3 \mu \mathrm{m}$ size range. A very large numberconcentration of FAP was measured at 11:00 in the size range between 1.4 and $2.1 \mu \mathrm{m}$ which was indicated by the red/crimson colour. There was a stark difference between both FAP profiles as the weekday period is dominated by the activities of the compost site leading to higher concentration of FAP whereas the weekend appears to revert to a more rural profile in which fungal spores are mainly released at night (Toprak and Schnaiter, 2013, Crawford et al., 2014).

Figs. 6a and 6b show histograms for size distributions vs fluorescence count for the particles measured over the full weekday period (Monday to Friday) and also the weekend period. The sizes of the particles ranged between 0.8 and $15 \mu \mathrm{m}$. Clearly particles $<3$ $\mu \mathrm{m}$ dominated the counts and displayed a bimodal size distribution for both periods. Previous FAP measurement campaigns that have used the WIBS also indicate that the highest concentrations of FAP occur with sizes $<3 \mu \mathrm{m}$ (Toprak and Schnaiter, 2013, Gabey et al., 2013, O'Connor et al., 2015). The two size groupings, which had the highest number concentrations were maximised at $\sim 1.1 \mu \mathrm{m}$ and $\sim 2.1 \mu \mathrm{m}$.

Due to the high time resolution of the WIBS it was possible to construct a profile of FAP trends with meteorological conditions. The Weather Station recorded weather parameters such as rainfall, temperature and humidity at 5 min intervals. These were then averaged to one-hour resolution periods and plotted along with the one-hour particle bins for the WIBS-4A. The values for wind speed and wind direction were taken from the site weather station at 15 -min intervals which were also averaged into one-hour intervals.

Diurnal weather/particle concentration profiles for the measurement campaign were constructed for the campaign period and are presented in Fig. 7.

Fig. 7 shows the relationship between the average diurnal concentrations of FAP (in one-hour time bins) with the averaged diurnal hourly measurements for the weather parameters of wind speed, temperature and relative humidity throughout the measurement campaign. No striking relationship was recorded. The occupational activities (such as agitation) which are evident from 09:00 to 17:00 in the local environment appear to overwhelm any effect that meteorological conditions may have had on FAP concentrations.

Fig. 8 (a) presents a profile of wind speed and direction for the duration of the campaign. These parameters are important as they determine which direction the bioaerosols are dispersed (Recer et al., 2001). It has been previously found that wind speed caused major variation in concentrations of bioaerosols measured with a WIBS at this particular compost site (O'Connor et al., 2015). Wind 


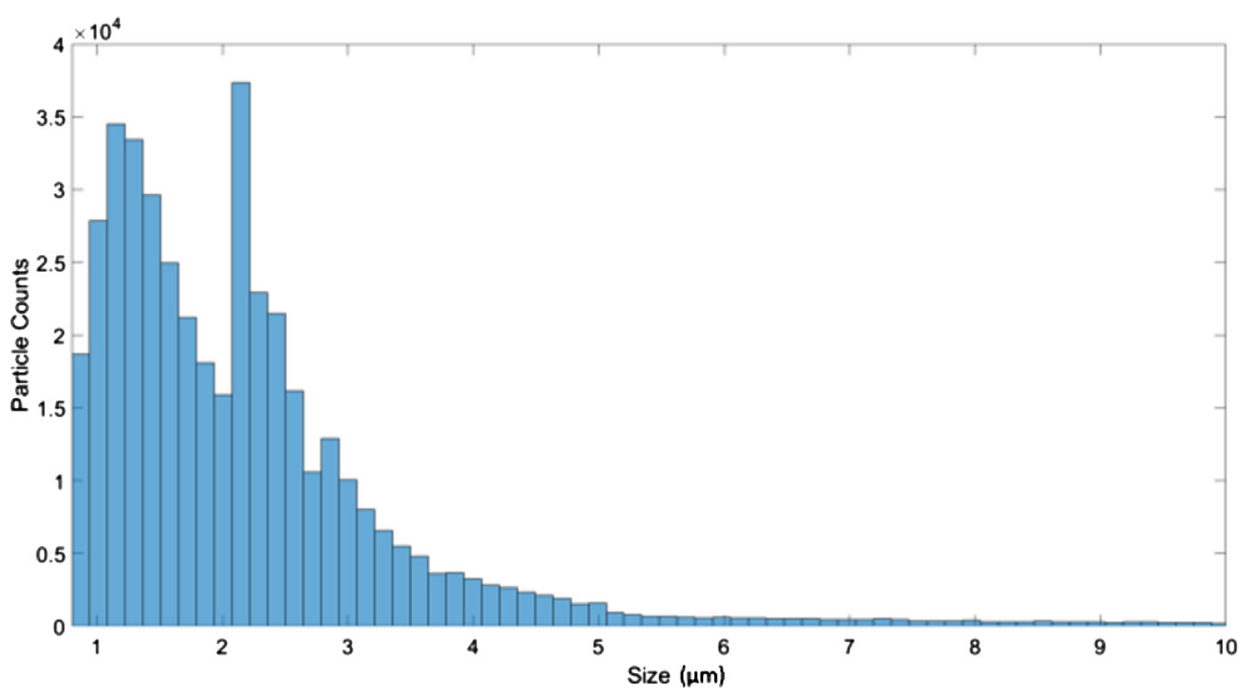

Fig. 6a. A histogram of the size distribution of the fluorescent particles measured over the weekday period.

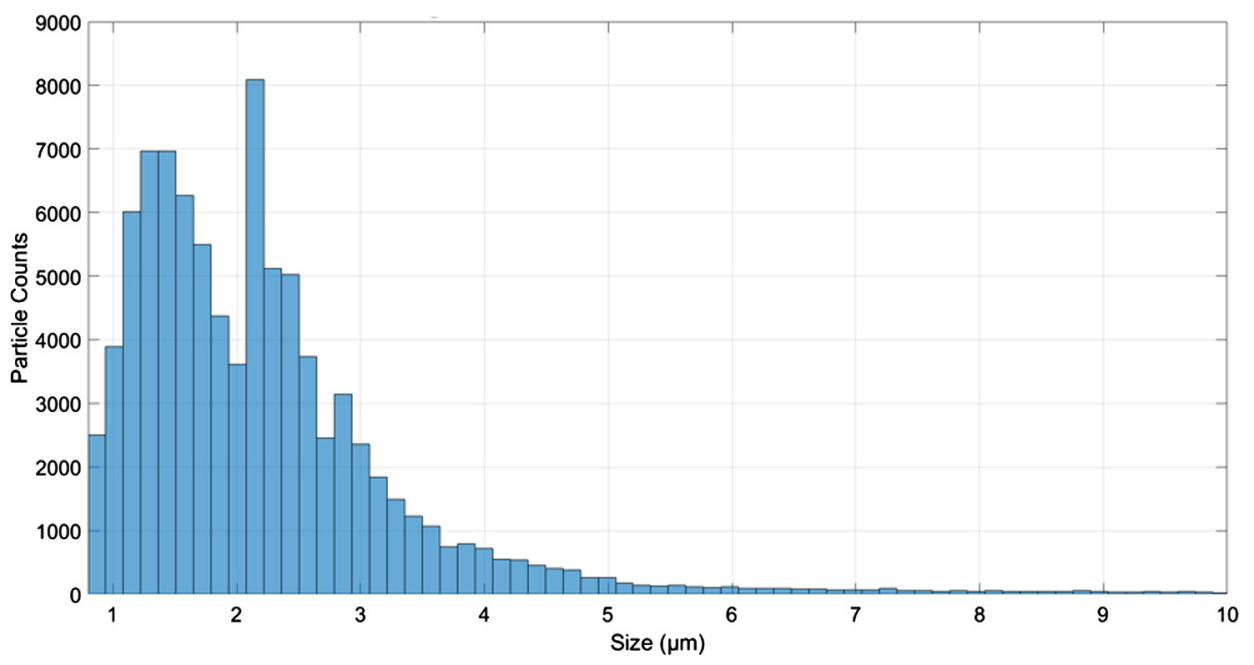

Fig. 6b. A histogram of the size distribution of the fluorescent particles measured over the weekend.

speed and direction measurements were recorded from the site weather station, which was located on the roof of the site office $\sim 20 \mathrm{~m}$ from ground level and therefore remote from any obstructions. The prevalent winds in the current study were from the west-northwest, northwest and north-northwest directions. The equipment on the compost site was positioned in the following arrangement: (i) the trailer, which houses the WIBS-4A was in the northern corner of the compost site; (ii) to the east there was a ditch separating it from a farm, which was approximately $30 \mathrm{~m}$ away; (iii) there was a compost wind row to the south of the trailer and the screener was located to the west. This latter machine was used to separate fine and coarse compost and, in operation, required rigorous agitation of the compost. Clearly such an activity would lead to large FAP concentrations in the surrounding air. The largest compost shed on-site was located north-west of the trailer and the bio-filter was due north.

Fig. 8(b) illustrates that the highest concentrations of FAP originated from the west-northwest and northwest direction, which was one of the three prevailing wind directions. The screening machine was west of the trailer and many of the FAP emissions from the screener would have been carried by the North-West wind into the path of the WIBS-4A.
The other two prevailing wind directions originated from the North-West and North-North-West directions. Surprisingly the concentrations associated with the latter two directions were relatively low as can be seen from the colour key (low concentrations indicated by a red colour). This observation can be explained by the location of the compost shed North-West of the trailer because it was obstructing winds from blowing FAP in the direction of the trailer.

Therefore wind speeds and directions do obviously play a part in naturally moving FAP around the site (O'Connor et al., 2015, Recer et al., 2001) but are less relevant when site activities are occurring.

Fig. 9 shows time series graphs constructed to summarise the daily concentrations recorded using the two approaches. Each hourly concentration was summed over the individual 24-h periods.

Fig. 9 shows consistent trends for the two contrasting methods. There were clearly increases and decreases of particulates that tracked for both FAP and spore measurements over the whole seven-day period. The largest discrepancy in measurements were found mid-week on 2nd March when optical microscopy revealed few PBAP but only a small decrease in levels were observed for the 

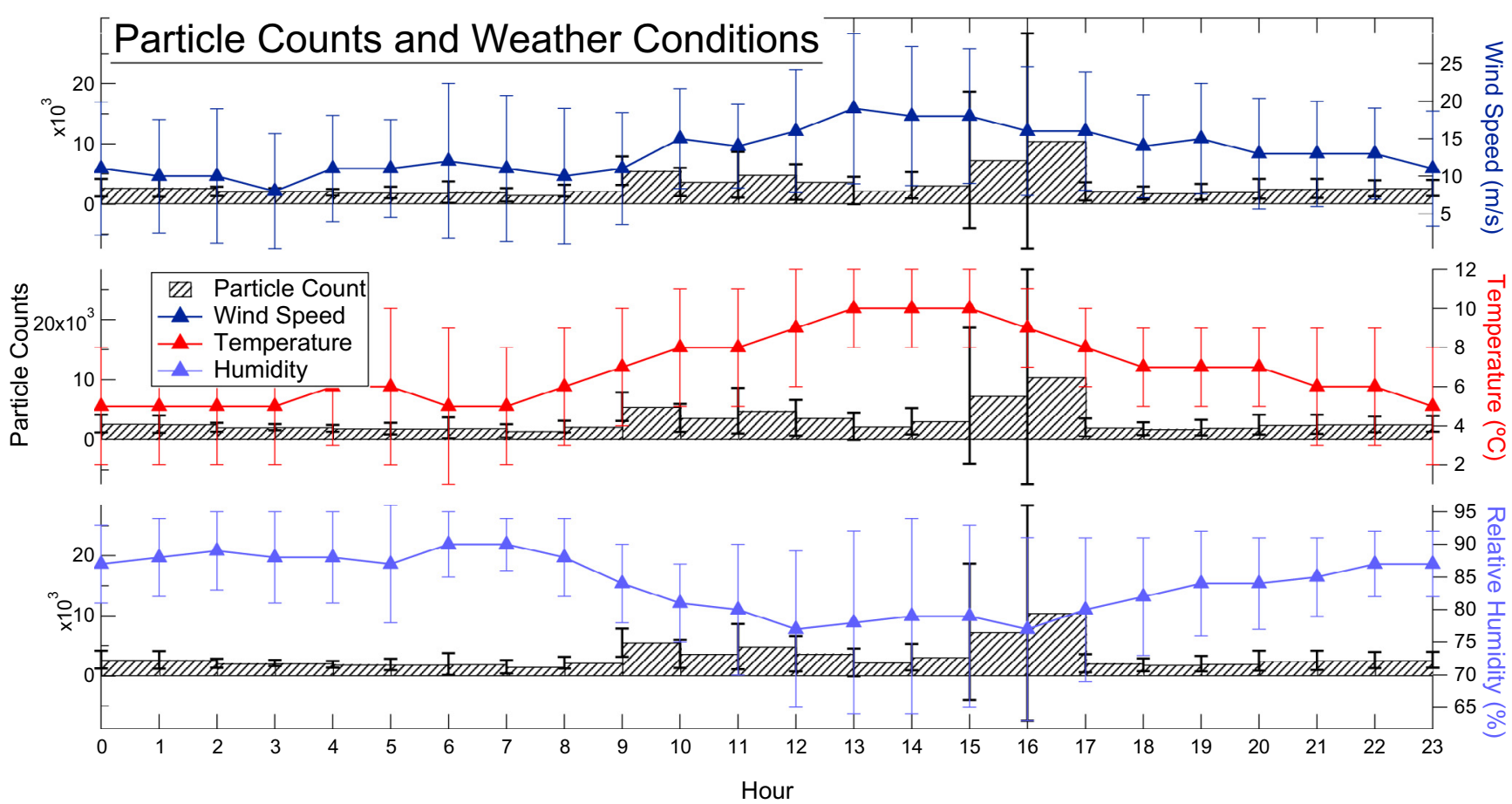

Fig. 7. Average diurnal profiles of FAP concentrations, with error bars as the standard deviation of the averaged values, plotted with weather parameters.
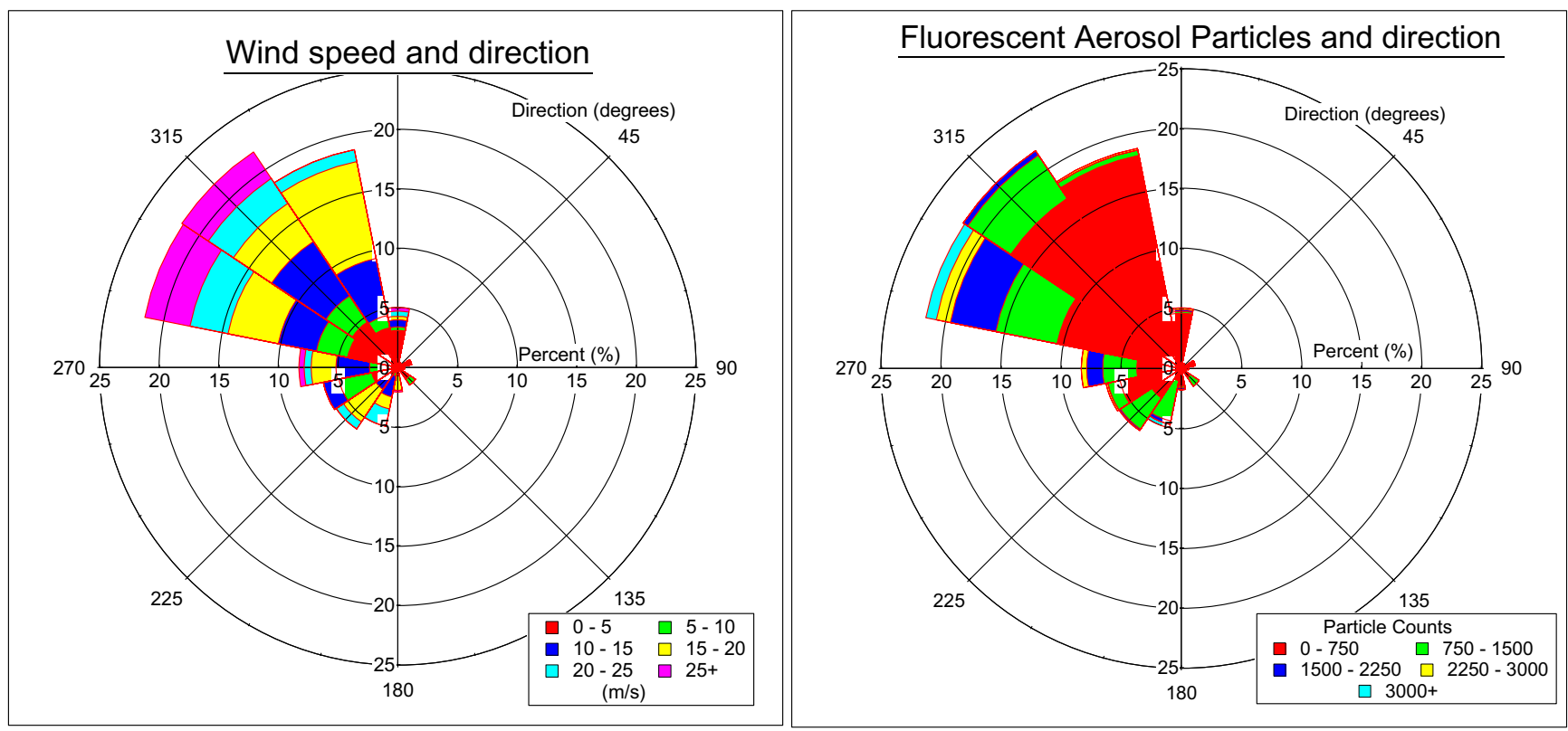

Fig. 8. (a) Wind rose diagram of wind speed and direction and (b) Fluorescent Aerosol Particles in terms of wind direction.

WIBS-4A. This could be due to loading being associated with PBAP $<2 \mu \mathrm{m}$ in size. The largest concentration of FAP/Spores measured by both techniques was observed on Thursday 3rd March. The levels measured that day were very large and tracked decreases in number concentrations were measured for both instruments over the following days. Of particular note is the fact that there is generally a large difference in the FAP concentrations by comparison with the measured spore concentrations. In fact, there is $\sim 200 \times$ the number of FAP measured by the WIBS approach than spores counted by optical microscopy. In part the observation can be explained by the differing size regimes that the two tech- niques monitor. The WIBS can measure bacteria (Hernandez et al., 2016) that is present on the compost site. Due to magnification limitations associated with many optical microscopes the SporeWatch has a low efficiency for measuring microorganisms less than $2 \mu \mathrm{m}$. This makes it a poor method for measuring bacteria (Eduarda and Heederik, 1998, Cartwright et al., 2009). There are numerous, potential fluorescent interferents that are often present on a rural green-waste sites. For example, HUmic LIke Substances (HULIS) originating from soil fugitives, primary particles with a transport origin and/or Secondary Organic Aerosols (SOA) from diesel exhausts. In principle then false positives can be monitored 


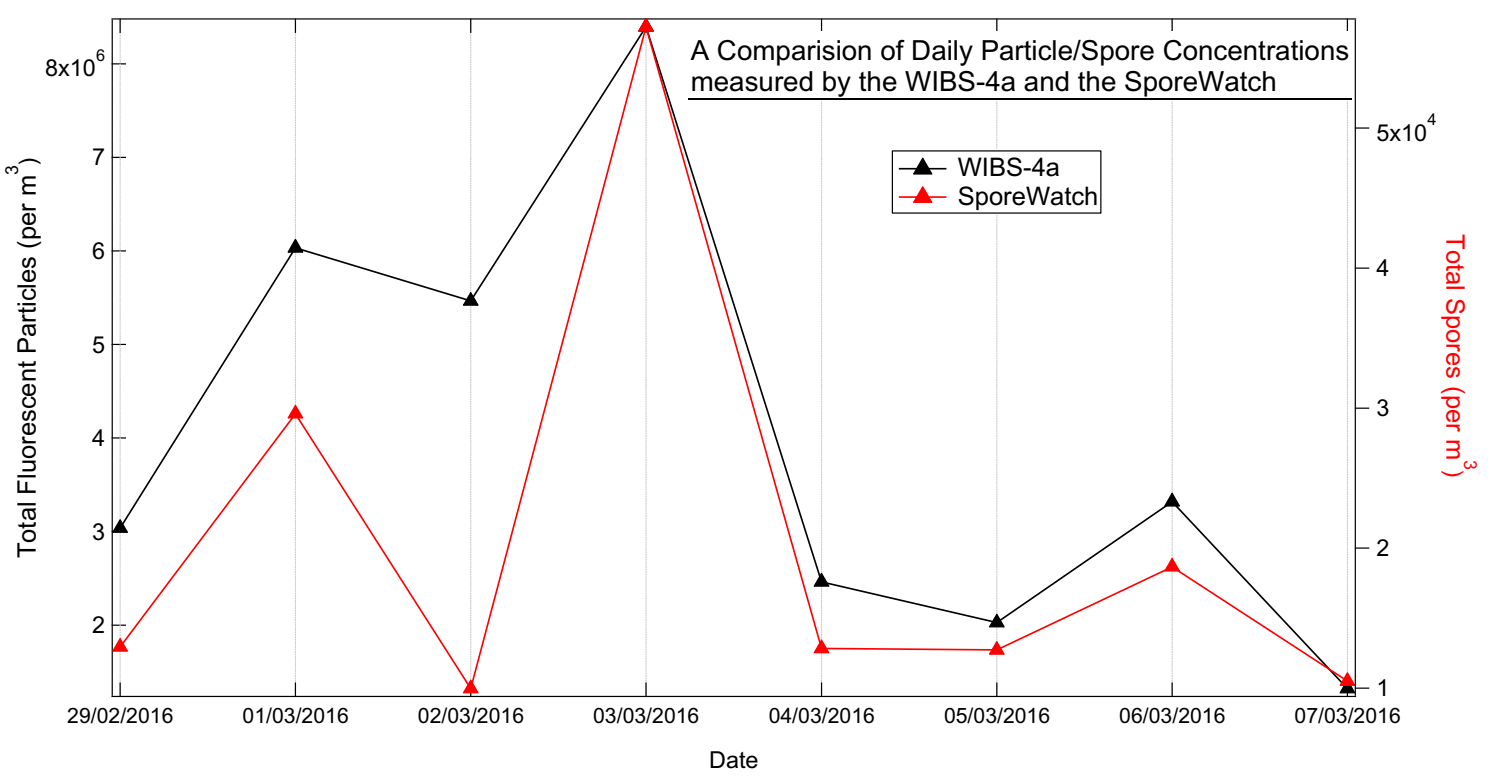

Fig. 9. A comparison of the Daily Particle/Spore Concentrations Measured by the WIBS-4A and the SporeWatch.

by WIBS (Gabey et al., 2013, Poehlker et al., 2012) but the fluorescence quantum yields of interferents are very low (Poehlker et al., 2012) in comparison to the PBAP biofluorophores (Poehlker et al., 2012, Healy et al., 2012, Gabey et al., 2013).

To provide a more detailed statistical treatment of the counting by the two contrasting techniques, linear regression was applied to the data as shown in Fig. 10. Hence, a co-efficient of determination, correlation coefficient and variance were calculated.

The resulting coefficient of determination $\left(R^{2}\right.$ value) was 0.7 . An important source of this variance was associated with the very low measurements made using the SporeWatch on Wednesday 2nd March. This observation may be due to the high wind speeds recorded on Wednesday, with an average speed of $24 \mathrm{~m} / \mathrm{s}$, thereby interfering with its impaction sampling ability. The correlation coefficient was 0.84 . This was reflected by the reasonably good overall trends in daily concentrations shown in Fig. 9.

Linear regression was then used to further compare the correlations obtained for the hourly concentrations of total spores measured by optical microscopy (y-axis) and FAP measured by the WIBS-4A (x-axis). This relationship is presented in Fig. 11.
The coefficient of determination ( $R^{2}$ value) for the hourly measurements was 0.45 . The correlation coefficient was 0.67 . Both values were smaller than their daily concentration counterparts because the time resolution for the data collected on the WIBS$4 \mathrm{~A}$ was much shorter than that possible with the SporeWatch/optical microscopy measurements. This difference would be expected to lead to an increase in variance. However, it is of note that the two methodologies are based on such different detection/counting techniques and time-resolutions that statistical comparisons may be of little relevance. They are presented here because so few studies have been performed previously and should help in the construction of any future data-bases for monitoring biowaste facilities.

An important spore counted on the compost site was Ustilago maydis, a smut fungus that is pathogenic on maize (Carlile et al., 2001, Brefort et al., 2009). It is therefore associated with the type of green-waste delivered by brewers and distillers.

Major measurements of it were recorded on 1st, 3rd and 4th March as shown in Fig. 12. Its size range is generally $\sim 8-10 \mu \mathrm{m}$ and spherical in morphology. It was determined with microscopy

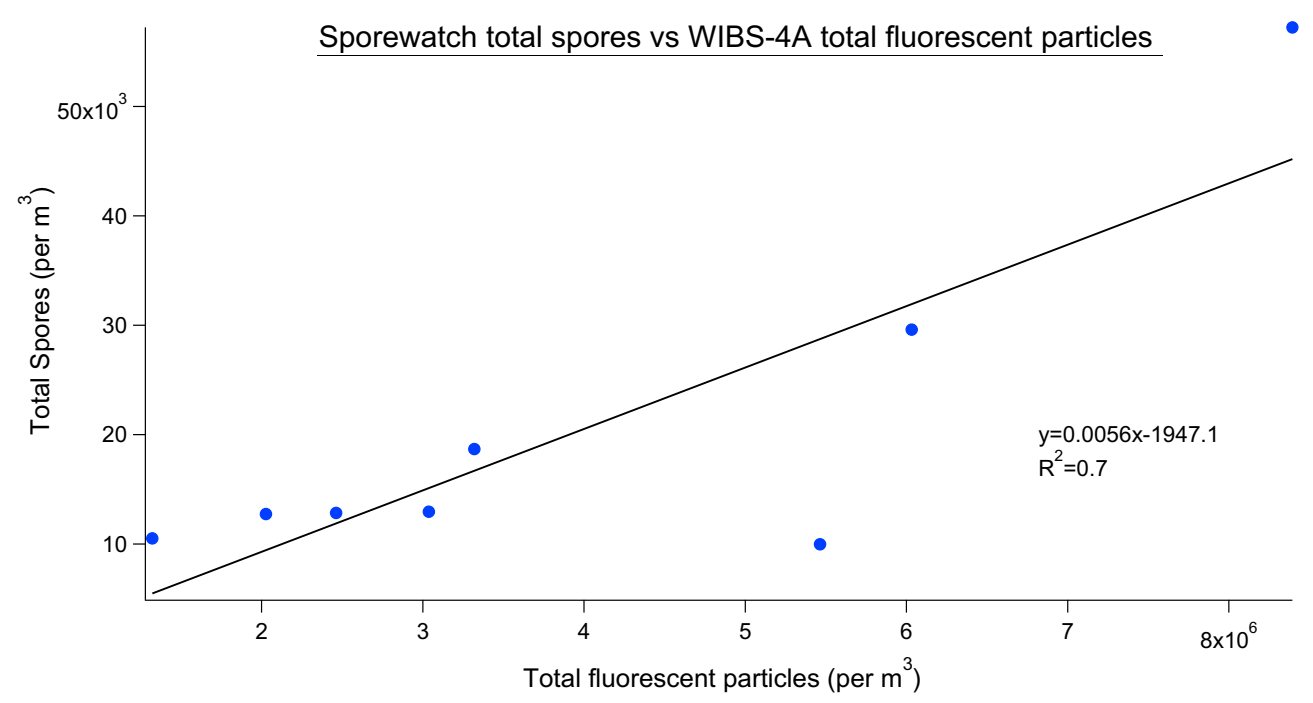

Fig. 10. Linear regression for SporeWatch and WIBS instrument for the daily concentrations. 


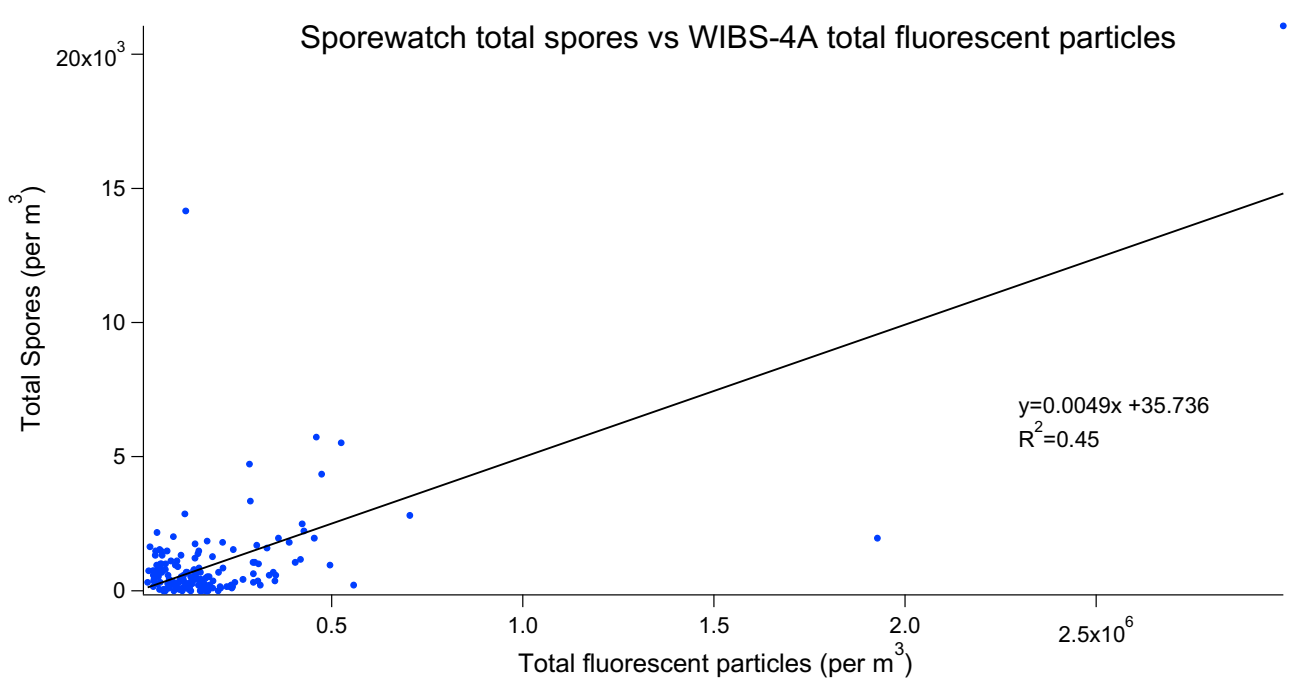

Fig. 11. Linear regression for SporeWatch and WIBS instrument for the hourly concentrations.

that the Ustilago maydis does not agglomerate into clusters, as observed for Aspergillus fumigatus. Hence a size range filter of 8$12 \mu \mathrm{m}$ was applied to the WIBS-4A fluorescence measurements. (Particles in the 11 and $12 \mu \mathrm{m}$ size range were included to ensure that any potentially larger Ustilago maydis spores were measured).

There is poor correlation between the results on 1st March when the presence of Ustilago maydis was recorded over several hours. However, there was much on-site activity over that day as it was the first in the working week and, as might be expected under such conditions, many fluorescent particles were recorded by WIBS-4A.

In contrast two excellent correlations between Ustilago maydis optical microscopy counts and FAP counts were observed over much shorter time scales on 3rd and 4th March at 16.00 and 09.00 respectively. The 4 th March measurement corresponded with a green-waste delivery made by a local distillery. The source of the spore is therefore likely associated with wheat, barley and maize. This finding is important because it shows that the WIBS approach can provide an early warning signal for Ustillago maydis, which is an important plant pathogen of maize. Monitoring of other occupational environments such as farms, brewers and distillers may therefore prove instructive.

The advantage of co-locating the SporeWatch with the WIBS-4A was that the traditional impaction approach determined Ustilago maydis to be present and their counts tracked FAP counts in the appropriate size range. The former measurements took days to become available whereas the WIBS-4A results were immediately available and with a much superior time resolution. Fig. 13a shows the real-time emissions of FAP over a short ( $18 \mathrm{~min}$.) period on the 3rd of March from 15:26 to 15:44. Fig. 13b presents a shorter period (4 min.) on the 4th of March from 09:06 to 09:10. This treatment highlights the excellent time-resolution capabilities of

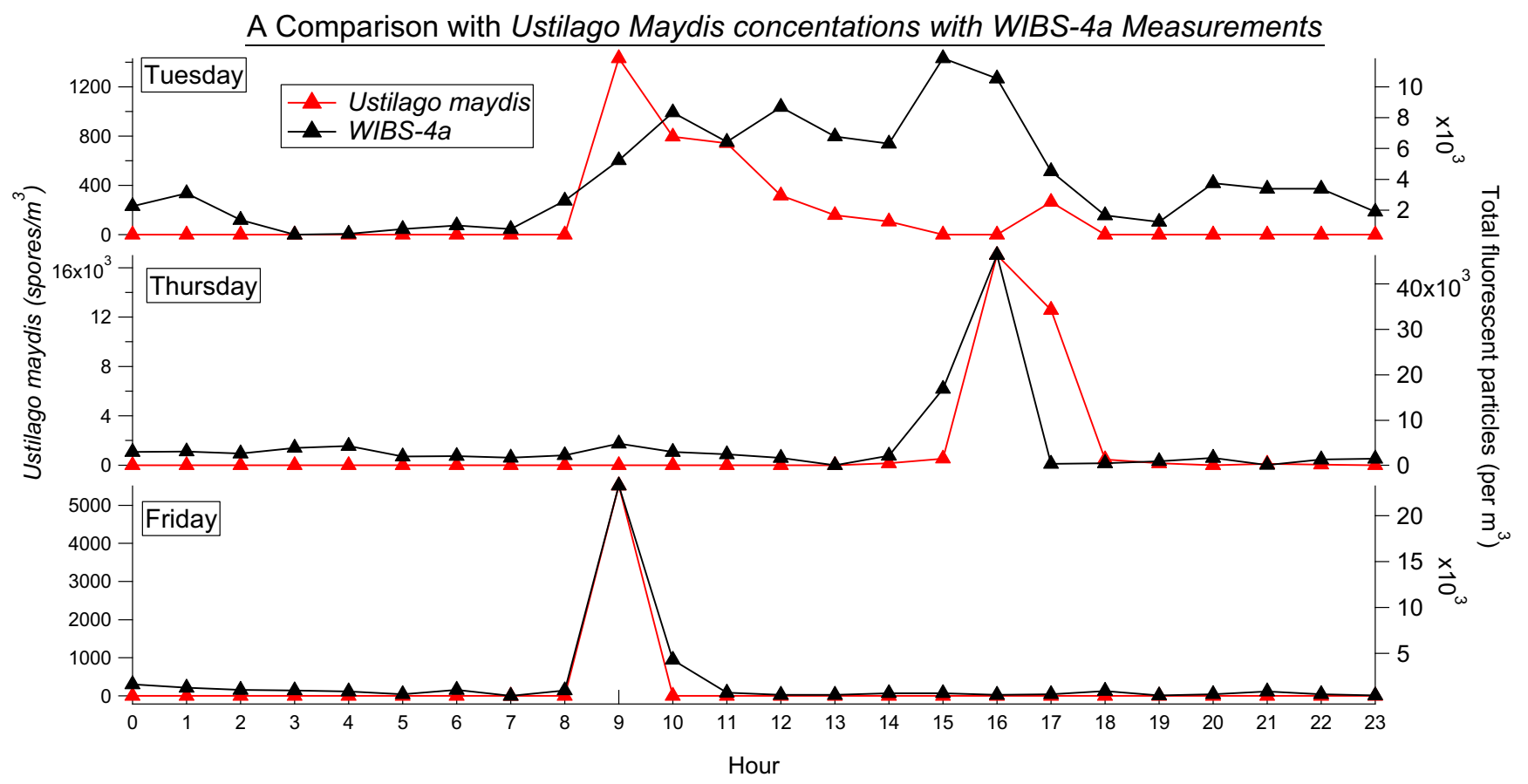

Fig. 12. Hourly concentration diurnal graphs for 1 st, 3rd, and 4th March. 


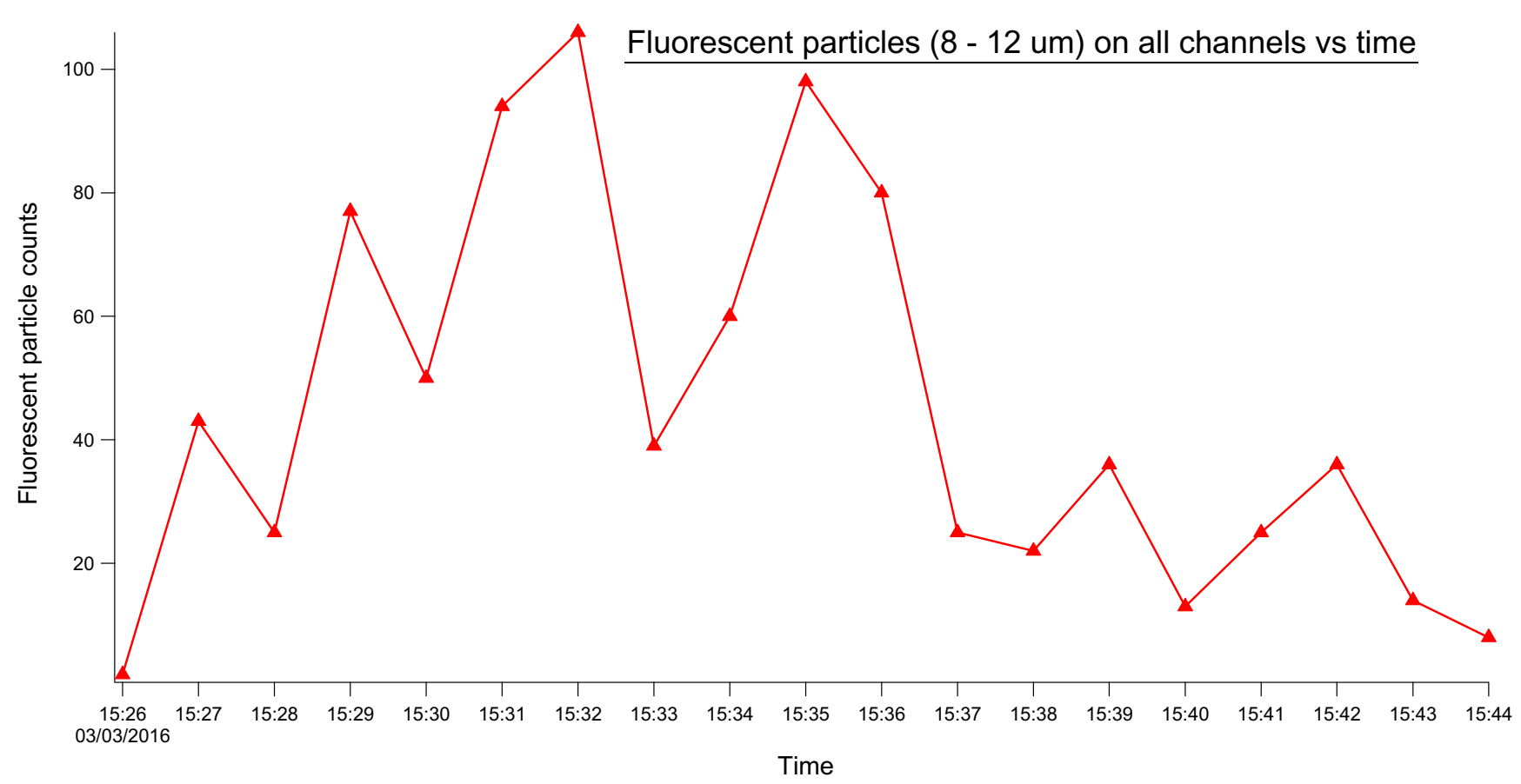

Fig. 13a. Time series of fluorescent particles $(8-12 \mu \mathrm{m})$ vs time.

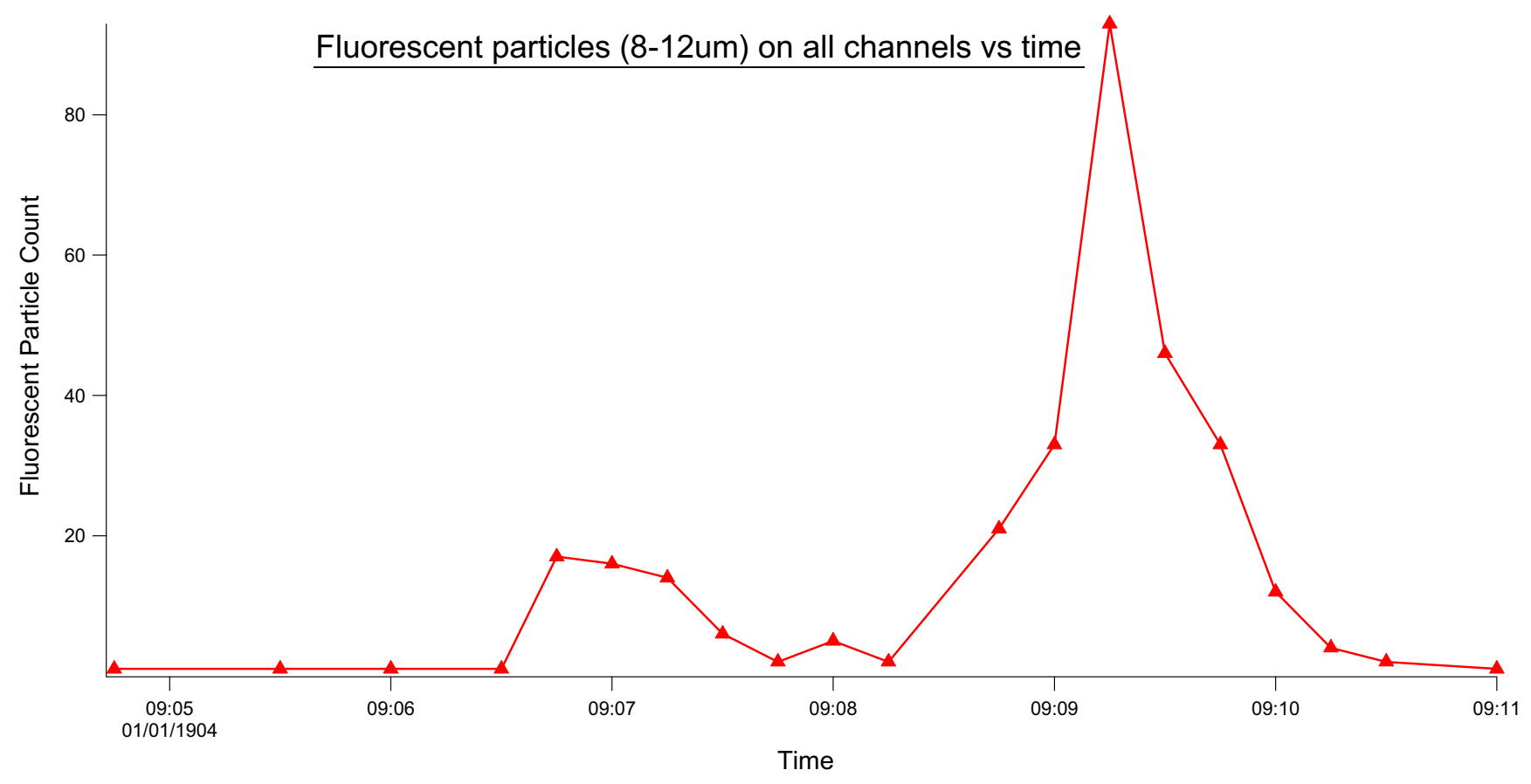

Fig. 13b. Time series of fluorescent particles $(8-12 \mu \mathrm{m})$ vs time.

WIBS (seconds) for real-time analysis compared to impaction/ microscopy with a $1 \mathrm{~h}$ resolution. High time resolution resolution data provides the opportunity to apply appropriate averaging times for different situations with regards to emissions.

The fluorescence trends of the Ustilago maydis spores were investigated across the FL1, FL2 and FL3 channels. Their intensities were graphed as shown in Figs. 14a and 14b for the time periods over which their emissions were highest e.g. 3rd and 4th March.
It is clear from Figs. 14a and 14b that the FL1 channel was the dominant channel with much higher intensities than the FL2 and FL3 channels. Indeed the FL2 and FL3 intensities tracked closely to each other. Detailed cluster analysis (e.g. K-means) combining fluorescence intensities (FL1, FL2 and FL3) with size and shape data could, in principle, be used to selectively distinguish what types of fluorescent particles are present e.g. Ustilago maydis, however this procedure is outside the scope of this report. 


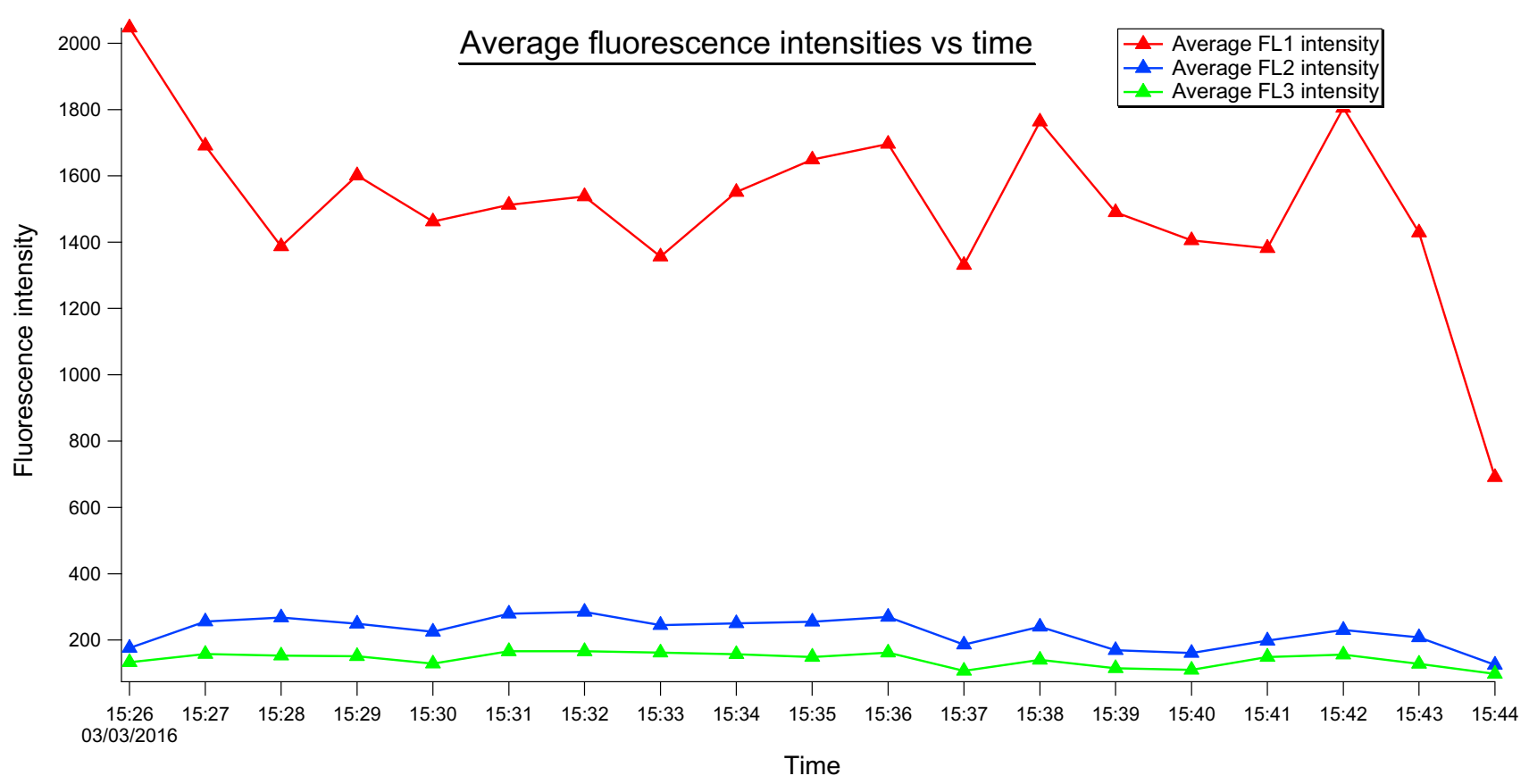

Fig. 14a. Fluorescence intensities vs time on the 3rd March.

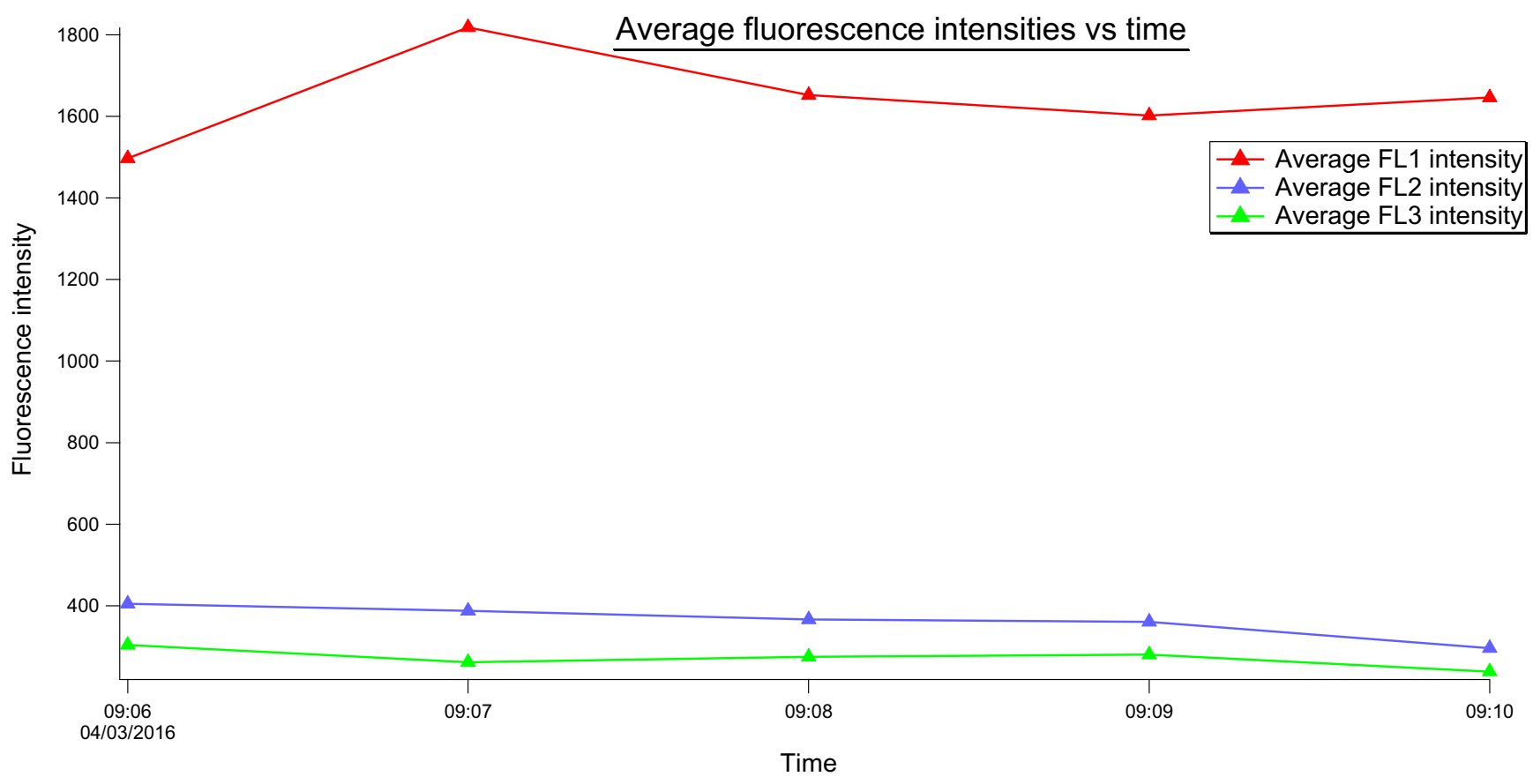

Fig. 14b. Fluorescence intensities vs time on the 4th March.

\section{Conclusion}

There were somewhat higher number concentrations of spores recorded by impaction/optical microscopy on weekdays at the green-waste site, with average hourly concentrations of 361 spores $/ \mathrm{m}^{3}$, as opposed to the weekend, which had average hourly concentrations of $252 \mathrm{spores} / \mathrm{m}^{3}$. However, looking at the averages neglects the fact that the release patterns of fungal spores were seen to be different between both periods. During the weekdays the highest concentrations of spores occurred during the working hours of the compost site (08:30-17:00) with an average hourly concentration of (2098 spores $\left./ \mathrm{m}^{3}\right)$ and can be attributed to the disturbance of spores by necessary activities such as deliveries or turning, shredding and screening of compost (O'Gorman, 2011, Recer et al., 2001, Van der Werf, 1996, Millner et al., 1980, Gillum and Levetin, 2008). The increased measurement between 07:00 and 11:00 on Sunday is worth mentioning as the site was formally closed at that time. To account for this observation it is possible that there was unmonitored on-site, activity then or that the effects from the one dry day experienced the day before caused the dispersal. 
The WIBS-4A instrumentation is capable of providing a far superior time-resolution for detecting on-site FAP (and therefore potential PBAP) than the traditionally employed off-site, technique i.e. Andersen sampling. The fluorescence spectroscopy measurements were able to provide data with a one second time resolution rather than hours. Such a real-time, on-site approach should be of particular interest and assistance when investigating specific events that may occur from time to time when producing compost not only from commercial green-waste sites but also from domestic composting. The PBAP events recorded here could not be picked up as a function of time using traditional sampling of culturable organisms. An example here is the measurement of high levels of FAP recorded on 3rd March at 15:26-15:44.

It would be possible to leave a WIBS-4A deployed full-time at any commercially operated compost site or occupational environment for an indefinite period of time. The data were collected in this study using remote off-site, computer control. This approach enables more descriptive temporal profiles of spore release even when the facility is closed. Furthermore the technique readily provides a more accurate profile of all bioaerosols (as well as nonfluorescent particles) as a function of normal working activities. Indeed the deployment of the WIBS apparatus indoors in the storage facilities and the staff cabins might be expected to prove to be of particular use for occupational health requirements.

A total FAP loading to determine whether a composting license should be issued or not might prove useful especially if it is activity dependent. Although not strictly equivalent to Aspergillus fumigatus CFU counts that currently underpin regulations in UK and Ireland it could be argued that all $\mathrm{PM}_{2.5}$, particularly examples that are fluorescent in nature are likely to lead to adverse health effects. Perhaps the WIBS could be used as a research tool to inform and improve standard site sampling regime designs. A current limitation of the WIBS as a regulatory instrument is that it measures all organism alive, dead and culturable whereas current regulatory methods are based on viable organisms' counts (Williams et al., 2013, Pankhurst et al., 2011). Further inter-comparisons of WIBS with these methods would be necessary and should be pursued. This limitation, of course, is also true for monitoring campaigns using q-PCR (Williams et al., 2013) and other sequencing methods (Le Goff et al., 2010).

In the work presented here, specific to Ustilago maydis, it is possible to propose a future measurement campaign near an agricultural environment in which maize is grown. There is a strong potential to monitor Ustilago maydis in real-time. As the spore is pathogenic on this crop it would be of importance to producers of maize to determine the concentrations of this spore in the ambient air around the crop. The measurements could lead to an indication of the contamination of the fungus on their crops.

\section{Acknowledgments}

We gratefully acknowledge financial support from the Irish Research Council "GOIPG/2015/3062" and the EPA (Ireland) under the OLBAS (2014-CCRP-MS.19) grant. Also we thank Aidan Stafford for his critical advice on waste management.

\section{References}

Abba, I., 2004. Are indoor molds causing a new disease. J. Allergy Clin. Immunol $113,1-6$.

Avery, L.M., Booth, P., Campbell, C., Tompkins, D., Hough, R.L., 2012. Prevalence and survival of potential pathogens in source-segregated green waste compost. Sci. Total Environ. 431, 128-138.

Beffa, T., Staib, F., Fischer, J.L., Lyon, P.F., Gumowski, P., Marfenina, O.E., DunoyerGeindre, S., Georgen, F., Roch-Susuki, R., Gallaz, L., Latge, J.P., 1998. Mycological control and surveillance of biological waste and compost. Med. Mycol. 36, $137-$ 145.
Brefort, T., Doehlemann, G., Mendoza-Mendoza, A., Reissmann, S., Djamei, A., Kahmann, R., 2009. Ustilago maydis as a pathogen. Ann. Rev. Phytopathol. 47, 423-445.

Carlile, M.J., Watkinson, S.C., Gooday, G.W., 2001. The Fungi. Gulf Professional Publishing.

Cartwright, C., Horrocks, S., Kirton, J., Crook, B., 2009. Review of methods to measure bioaerosols from composting sites. Environ. Agency. SC040021/SR3.

Chaudhary, N., Marr, K.A., 2011. Impact of Aspergillus fumigatus in allergic airway diseases. Clin. Transl. Allergy 1. 4-4.

Cohen, A.J., Ross Anderson, H., Ostro, B., Pandey, K.D., Krzyzanowski, M., Künzli, N., Gutschmidt, K., Pope, A., Romieu, I., Samet, J.M., 2005. The global burden of disease due to outdoor air pollution. J. Toxicol. Environ. Health, Part A 68, 13011307.

Crawford, I., Robinson, N.H., Flynn, M.J., Foot, V.E., Gallagher, M.W., Huffman, J.A., Stanley, W.R., Kaye, P.H., 2014. Characterisation of bioaerosol emissions from a Colorado pine forest: results from the beachon-rombas experiment. Atmos. Chem. Phys. 14, 8559-8578.

Després, V.R., Alex Huffman, J., Burrows, S.M., Hoose, C., Safatov, A.S., Buryak, G., Fröhlich-Nowoisky, J., Elbert, W., Andreae, M.O., Pöschl, U., Jaenicke, R., 2012. Primary biological aerosol particles in the atmosphere: a review. Tellus, Series B: Chem. Phys. Meteorol. 64.

Eduarda, W., Heederik, D., 1998. Methods for quantitative assessment of airborne levels of noninfectious microorganisms in highly contaminated work environments. Am. Ind. Hygiene Assoc. 59, 113-127.

Elbert, W., Taylor, P.E., Andreae, M.O., Pöschl, U., 2007. Contribution of fungi to primary biogenic aerosols in the atmosphere: Wet and dry discharged spores, carbohydrates, and inorganic ions. Atmos. Chem. Phys. 7, 4569-4588.

Fischer, G., 2000. Comparison of Microbiological and Chemical Methods for Assessing the Exposure to Air Borne Fungi in Composting Plants (PhD thesis). Shaker, NY.

Fischer, J.L., Beffa, T., Lyon, P.-F., Aragno, M., 1998. Aspergillus fumigatus in windrow composting: effect of turning frequency. Waste Manage. Res. 16, 320-329.

Gabey, A.M., Gallagher, M.W., Whitehead, J., Dorsey, J.R., Kaye, P.H., Stanley, W.R., 2010. Measurements and comparison of primary biological aerosol above and below a tropical forest canopy using a dual channel fluorescence spectrometer. Atmos. Chem. Phys. 10, 4453-4466.

Gabey, A.M., Vaitilingom, M., Freney, E., Boulon, J., Sellegri, K., Gallagher, M.W., Crawford, I.P., Robinson, N.H., Stanley, W.R., Kaye, P.H., 2013. Observations of fluorescent and biological aerosol at a high-altitude site in central France. Atmos. Chem. Phys. 13, 7415-7428.

Gillum, S.J., Levetin, E., 2008. The air spora close to a compost facility in Northeast Oklahoma: Part I-spore trap sampling. Aerobiologia 24, 3-12.

Healy, D.A., Huffman, J.A., O'Connor, D.J., Pöhlker, C., Pöschl, U., Sodeau, J.R., 2014. Ambient measurements of biological aerosol particles near Killarney, Ireland: a comparison between real-time fluorescence and microscopy techniques. Atmos. Chem. Phys. 14, 8055-8069.

Healy, D.A., O'Connor, D.J., Sodeau, J.R., 2012. Measurement of the particle counting efficiency of the "Waveband Integrated Bioaerosol Sensor" model number 4 (WIBS-4). J. Aerosol Sci. 47, 94-99.

Hernandez, M., Perring, A.E., McCabe, K., Kok, G., Granger, G., Baumgardner, D. 2016. Chamber catalogues of optical and fluorescent signatures distinguish bioaerosol classes. Atmos. Meas. Technol. 9, 3283-3292.

Hirst, J.M., 1952. An automatic volumetric spore trap. Ann. Appl. Biol. 39, 257-265. Horner, W., Helbling, A., Salvaggio, J., Lehrer, S., 1995. Fungal allergens. Clin. Microbiol. Rev. 8, 161-179.

Hryhorczuk, D., Curtis, L., Scheff, P., Chung, J., Rizzo, M., Lewis, C., Keys, N., Moomey, M., 2001. Bioaerosol emissions from a suburban yard waste composting facility. Ann. Agric. Environ. Med. 8, 177-185.

Kaye, P.H., Hirst, E., Foot, V., Clark, J.M., Baxter, K.A., 2004. Low-cost multi-channel aerosol fluorescence sensor for networked deployment. In: Proceedings of SPIE - The International Society for Optical Engineering, pp. 388-398.

Kaye, P.H., Stanley, W.R., 2014. Fluid-borne particle detector. Google Patents.

le Goff, O., Bru-Adan, V., Bacheley, H., Godon, J.J., Wéry, N., 2010. The microbial signature of aerosols produced during the thermophilic phase of composting. J. Appl. Microbiol. 108, 325-340.

Millner, P., Marsh, P., Snowden, R., Parr, J., 1977. Occurrence of Aspergillus fumigatus during composting of sewage sludge. Appl. Environ. Microbiol. 34, 765-772.

Millner, P.D., Bassett, D.A., Marsh, P.B., 1980. Dispersal of Aspergillus fumigatus from sewage sludge compost piles subjected to mechanical agitation in open air. Appl. Environ. Microbiol. 39, 1000-1009.

O'Connor, D.J., Healy, D.A., Sodeau, J.R., 2015. A 1-month online monitoring campaign of ambient fungal spore concentrations in the harbour region of Cork, Ireland. Aerobiologia 31, 295-314.

O'Connor, D.J., Daly, S.M., Sodeau, J.R., 2015. On-line monitoring of airborne bioaerosols released from a composting/green waste site. Waste Manage. (Oxford) 42, 23-30.

O'Gorman, C.M., 2011. Airborne Aspergillus fumigatus conidia: a risk factor for aspergillosis. Fungal Biol. Rev. 25, 151-157.

Pankhurst, L., Deacon, L., Liu, J., Drew, G., Hayes, E.T., Jackson, S., Longhurst, P., Longhurst, J., Pollard, S., Tyrrel, S., 2011. Spatial variations in airborne microorganism and endotoxin concentrations at green waste composting facilities. Int. J. Hygiene Environ. Health 214, 376-383.

Pinnick, R.G., Hill, S.C., Nachman, P., Pendleton, J.D., Fernandez, G.L., Mayo, M.W., Bruno, J.G., 1995. Fluorescence particle counter for detecting airborne bacteria and other biological particles. Aerosol Sci. Technol. 23, 653-664. 
Poehlker, C., Huffman, J.A., Poeschl, U., 2012. Autofluorescence of atmospheric bioaerosols - fluorescent biomolecules and potential interferences. Atmos. Meas. Technol. 5, 37-71.

Pöschl, U., 2005. Atmospheric aerosols: composition, transformation, climate and health effects. Angewandte Chemie - Int. Ed. 44, 7520-7540.

Recer, G.M., Browne, M.L., Horn, E.G., Hill, K.M., Boehler, W.F., 2001. Ambient air levels of Aspergillus fumigatus and thermophilic actinomycetes in a residential neighborhood near a yard-waste composting facility. Aerobiologia 17, 99-108.

Sanchez-Monedero, M., Stentiford, E., 2003. Generation and dispersion of airborne microorganisms from composting facilities. Process Saf. Environ. Prot. 81, 166170.

Sanchez-Monedero, M.A., Stentiford, E.I., Urpilainen, S.T., 2005. Bioaerosol generation at large-scale green waste composting plants. J. Air Waste Manage. Assoc. 55, 612-618.

Simon-Nobbe, B., Denk, U., Pöll, V., Rid, R., Breitenbach, M., 2007. The spectrum of fungal allergy. Int. Archives Allergy Immunol. 145, 58-86.

Sugui, J.A., Losada, L., Wang, W., Varga, J., Ngamskulrungroj, P., Abu-Asab, M., Chang, Y.C., O'Gorman, C.M., Wickes, B.L., Nierman, W.C., 2011. Identification and characterization of an Aspercillus fumigatus "supermater" pair. MBio 2, 234-311.

Taha, M., Pollard, S.J., Sarkar, U., Longhurst, P., 2005. Estimating fugitive bioaerosol releases from static compost windrows: feasibility of a portable wind tunnel approach. Waste Manage. (Oxford) 25, 445-450.
Taha, M.P.M., Drew, G.H., Longhurst, P.J., Smith, R., Pollard, S.J.T., 2006. Bioaerosol releases from compost facilities: Evaluating passive and active source terms at a green waste facility for improved risk assessments. Atmos. Environ. 40, 11591169.

Toprak, E Schnaiter, M., 2013. Fluorescent biological aerosol particles measured with the Waveband Integrated Bioaerosol Sensor WIBS-4: laboratory tests combined with a one year field study. Atmos. Chem. Phys. 13, 225-243.

van der Werf, P., 1996. Bioaerosols at a Canadian composting facility. BioCycle 37 $78-83$.

Vincken, W., Roels, P., 1984. Hypersensitivity pneumonitis due to Aspergillus fumigatus in compost. Thorax 39, 74-75.

Wéry, N., 2014. Bioaerosols from composting facilities-a review. Front. Cell. Infect. Microbiol. 4, 42.

Williams, M., Lamarre, B., Butterfield, D., Tyrrel, S., Longhurst, P., Drew, G., AlAshaab, R., Nelson, A., Gladding, T., Simpson, A., 2013. Monitoring bioaerosol and odour emissions from composting facilities. Environ. Agency, WR1121.

Womiloju, T.O., Miller, J.D., Mayer, P.M., Brook, J.R., 2003. Methods to determine the biological composition of particulate matter collected from outdoor air. Atmos. Environ. 37, 4335-4344. 